\title{
Influence of Nonlinearity of Soil Response on Characteristics of Ground Motion
}

\author{
Olga Pavlenko \\ Institute of Physics of the Earth, Russian Academy of Sciences \\ Russia
}

\section{Introduction}

Recent earthquakes, such as the 1985 Michoacan earthquake, the 1989 Loma Prieta earthquake, the 1994 Northridge earthquake, and the 1995 Kobe earthquake provided new experimental data on the soil behavior in strong ground motion, in particular, on the liquefaction phenomena, and discussions on the nonlinearity of soil behavior were induced (Lomnitz et al., 1995; Aguirre \& Irikura, 1997; Field et al., 1997; O'Connell, 1999, etc.). Though nonlinear elastic properties of soils were studied in multiple laboratory experiments, and valuable laboratory experimental data are accumulated sometimes, this is not sufficient for understanding the soil behavior in situ, because soils often represent multicomponent systems containing water, air, gases, etc., and strong ground motion can induce movement and redistribution of these components, i.e., changes in the properties of the soils. Experimental data on the soil behavior in strong motion in situ are still few, fragmental, and non-representative; and accumulation of these data is important for improving our understanding of soil behavior in strong motion.

In strong ground motion Hooke's law does not hold for subsurface soils, i.e., soils should be taken as nonlinear systems transforming incident seismic signals into movement on the surface. For studying nonlinear properties of systems, effective methods are developed in system analysis, so-called nonlinear system identification technique, based on the determination of higher-order impulse characteristics of the systems. An output of a nonlinear system is represented as the Volterra-Wiener series, i.e., a sum of the response of a linear system to the input signal and a number of nonlinear corrections, which are due to quadratic, cubic nonlinearity, and nonlinearities of higher (the 4-th, 5-th, etc.) orders. If we know the input and output of a nonlinear system, we can judge regarding the types and quantitative characteristics of the system nonlinearity (Marmarelis \& Marmarelis, 1978). Nonlinear identification of soils in various geotechnical conditions seems to be promising, because it allows a better understanding of the behavior of soils and structures in strong ground motion. However, to apply methods of system analysis to studying nonlinear properties of soils, knowledge of stress-strain relations in the soil layers in strong motions is required. In this section, a method of estimation of nonlinear stress-strain relations in soils in strong ground motion is proposed based on vertical array data.

Numerous methods and programs developed for calculating the ground response in strong motion in various conditions do not allow estimation of stress-strain relations in soil layers in situ. Moreover, in cases of strong nonlinearity, there often remains some disagreement 
between the observed and simulated records. As is known, equivalent linear models (SHAKE, QUAD-4, FEADAM, LUSH, FLUSH) are not applicable for calculation of such complex phenomena as soil liquefaction. Programs DESRA (Lee \& Finn, 1978), TARA and their modifications (Finn et al., 1986; Finn \& Yogendrakumar, 1989) allow determination of the possible level of the pore pressure and the possibility of liquefaction, and they can be applied for the analysis of soil behavior after liquefaction. Changes in the pore pressure are related to the volumetric deformations in soils in drained conditions, and one-dimensional diffusion is included in the algorithm. Programs DYSAC2, DYNAFLOW, and SWANDYNE are considered to provide the best results (Arulanandan et al., 1995). Equations of motion of the liquid and solid phases are related to the equation of conservation of matter. Generation and dissipation of the pore pressure are connected with the deformation of the solid matrix due to the Biot equations (Biot, 1956). However, in every case simplifications and assumptions are applied, concerning the medium properties, as well as the mechanisms of the processes, therefore, any uncertainties and mistakes in modeling lead to an improper calculation of the soil movement.

At the same time, records of strong ground motion provided by seismic vertical arrays allow estimation of stress-strain relations in soil layers in situ. This chapter describes the method of estimation of stress-strain relations developed by Pavlenko \& Irikura (2003) and its application to 1995 Kobe, 2000 Tottori, and 1999 Chi-Chi earthquakes. The method allows us to trace temporal changes in the stress-strain relations. Since the estimates are based only on real measurements, they are free of theoretical approximations and physical assumptions concerning mechanisms of processes arising in the medium in strong ground motion.

\section{Estimation of nonlinear time-dependent soil behavior in strong ground motion based on vertical array data}

Vertical array records of the 1995 Kobe earthquake were processed for three recording sites, Port-Island, SGK, and TKS. Distances to the closest point on the fault line are $2 \mathrm{~km}, 6 \mathrm{~km}$, and $16 \mathrm{~km}$, respectively. Figure 2.1 shows the locations of the sites, the major principal axes, and the epicenters of the main shock and aftershocks summarized by Disaster Prevention Research Institute of Kyoto University.

At Port Island, the vertical array contains four three-component accelerometers, installed at GL-0 m, GL-16 m, GL-32 m, and GL-83 m; the arrays at SGK and TKS sites consist of three three-component devices at GL-0 m, GL-24.9 m, and GL-97 m, and GL-0 m, GL-25 m, and GL-100 m, respectively (Fig. 2.2). We checked the directional drifts of the accelerometers by calculating the horizontal orbits of the long-period particle motions for the main shock and the aftershocks at different depths at the three sites. At Port Island, N19oW rotation at GL-83 $\mathrm{m}$ was detected and corrected; at SGK site, a reverse of NS component and N6 $\mathrm{W}$ rotation at GL-24.9 $\mathrm{m}$ and a reverse of NS component and N34 $\mathrm{E}$ rotation at GL-97 $\mathrm{m}$ were detected and corrected. At TKS site, N23W rotation at GL-25 $\mathrm{m}$ and N9॰E rotation at GL-100 $\mathrm{m}$ were detected and corrected. All these corrections agree with the conclusions of other authors.

The materials at the three sites are similar to one another: reclaimed soil, clays, sands, and gravel (Fig. 2.2). The profiling data at Port Island used for nonlinear simulation were taken from (Aguirre \& Irikura, 1997). Shear wave velocity, shear modulus degradation, and maximum shear strain at SGK and TKS sites were taken from Soeda et al. (1999). These data were used to calculate the shear stress in failure $\tau_{\max }$ and the low-strain shear modulus $G_{\max }$ in different layers, following Seed et al. (1984) and Sun et al. (1988). P-wave velocities, when 
exceeding $\sim 1000 \mathrm{~m} / \mathrm{s}$, indicate saturation of soils with water. The underground water level lay at about $13 \mathrm{~m}$ at Port Island and $\sim 3-5 \mathrm{~m}$ at SGK and TKS. The deepest layers were Pleistocene gravely soils and the upper layers consist of alternating Pleistocene gravel/clay layers, Holocene sand/clay layers and fill (Sato et al., 1996).

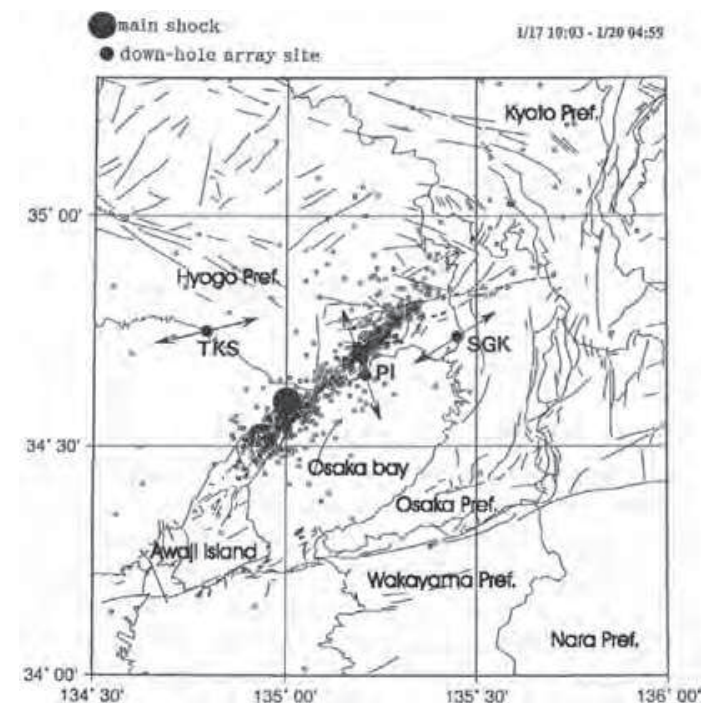

Fig. 2.1. Locations of vertical array sites Port Island (PI), SGK, and TKS around Osaka bay, the major principal axes, and the epicenters of the main shock and aftershocks (derived from Sato et al., 1996).
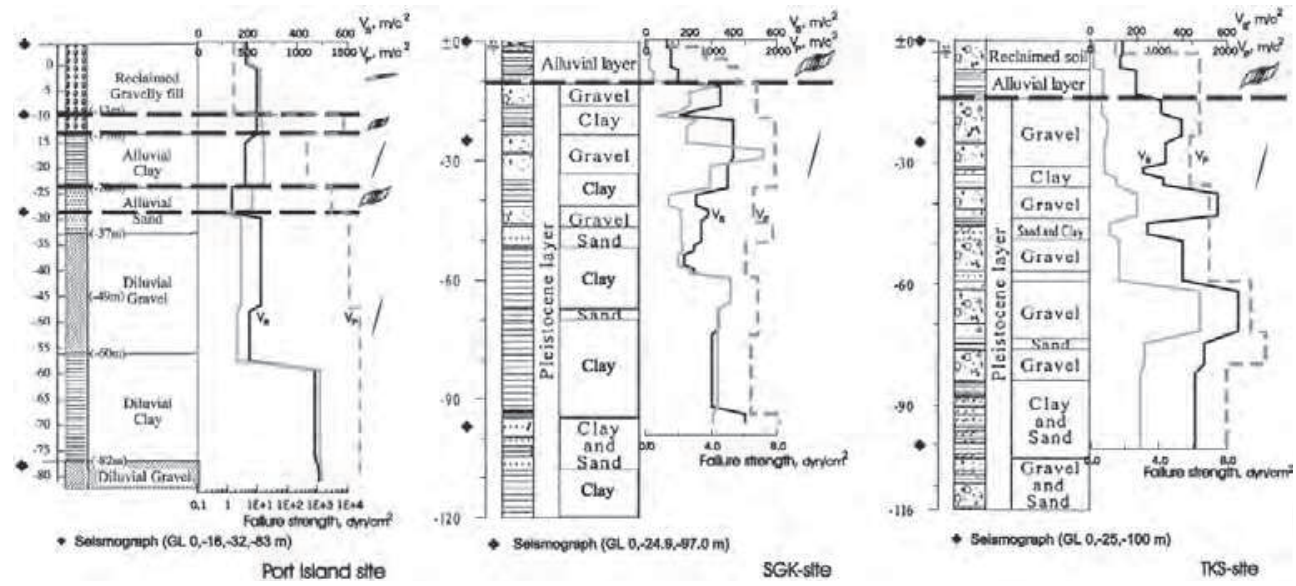

Fig. 2.2. The ground profiles and characteristic types of stress-strain relations at different depths at Port Island, SGK, and TKS sites.

To estimate the stress-strain relations in different layers, vertical array records of strong motion and the profiling data were used. We applied the modified algorithm of calculation 
of the propagation of a vertically incident shear wave in soil layers up to the surface, based on the lumped mass method (Joyner \& Chen, 1975), and combined it with the method of "trial and error" to find the stress-strain relations showing the best agreement between the observed and simulated records. In our computations, stress and strain are normalized in the manner used by Hardin \& Drnevich (1972): stress is normalized by multiplying by $1 / \tau_{\max }$ and strain is normalized by multiplying by $G_{\max } / \tau_{\max }$. For calculations, the studied medium from the surface down to the location of the deepest device was divided into groups of layers, for which certain types of stress-strain relations were assumed (Fig. 2.2). Three main types of stress-strain curves were considered:

1. Those that are similar to laboratory experiments by Hardin \& Drnevich (1972), to describe the behavior of dense soils at depths;

2. Those of "soft" type, similar to type (1), but with greater slope, being close to horizontal for large strains, for liquefied soils;

3. Those of "hard" type, declining to the stress axis at large strains, for water-saturated soils (terms "soft" and "hard" type stress-strain curves were introduced by Zvolinskii, 1982).

Sets of such curves were generated, and item-by-item examination was applied to find groups of curves showing the best-fit approximation to the observed data.

To account for temporal changes in the soil behavior, the records were divided into intervals of 1.5-seconds duration. Within each interval, the stress-strain relations were assumed to be stationary, and vary for different intervals.

Calculations (for horizontal components) were performed (i.e., the "best-fit" stress-strain relations in the layers were determined) successively, interval by interval. No discontinuities occur at the boundaries of the intervals, because, in the next interval, the whole cycle of loading (or unloading) was recalculated for the new curve from its beginning.

The results of the simulation with the "best-fit" stress-strain relations show a good agreement between the observed and simulated records at the three sites. The most intense and complex movements and liquefaction were observed at Port Island. The strongest horizontal accelerations were measured at the deepest point of $83 \mathrm{~m}$, such as, $\sim 500 \mathrm{Gal}$ for the EW component and $\sim 600 \mathrm{Gal}$ for the NS component. According to the material structure and the results obtained in the previous analysis (Kawase et al., 1995), the medium was divided into five groups of layers, for which certain types of stress-strain relations were assumed (Fig. 2.2). Since liquefaction occurred in the upper layers, curves of type (2) were applied for surface soils above the level of the underground water $(0-13 \mathrm{~m})$. Soil layers at depths 13-18 $\mathrm{m}$ and 27-32.5 $\mathrm{m}$ are reclaimed gravely fill and alluvial sand saturated with water, therefore, curves of type (3) were used to describe the soil behavior in these layers (Fig. 2.2). Peaks, or sharp increases in the amplitudes of the observed records at depths of 16 $\mathrm{m}$ and $32 \mathrm{~m}$ confirm that curves of type (3) are relevant in this case. Stress-strain curves of type (1), which are considered to be typical for dense soils at depth, were assumed for alluvial clay layers at 18-27 m and for deep diluvial layers below $32.5 \mathrm{~m}$. For successive 1.5second time intervals, the groups of stress-strain relations were found, showing the best-fit approximation to the observed records. Figure 2.3 shows the observed and simulated records (a) and the obtained stress-strain relations at different depths (b) for ten successive time intervals.

The most noticeable changes in the soil behavior were observed in layers near the surface, in the upper $13 \mathrm{~m}$ : the stress-strain relations become more and more sloping with time, showing a substantial progressive reduction of the shear modulus and liquefaction. At 

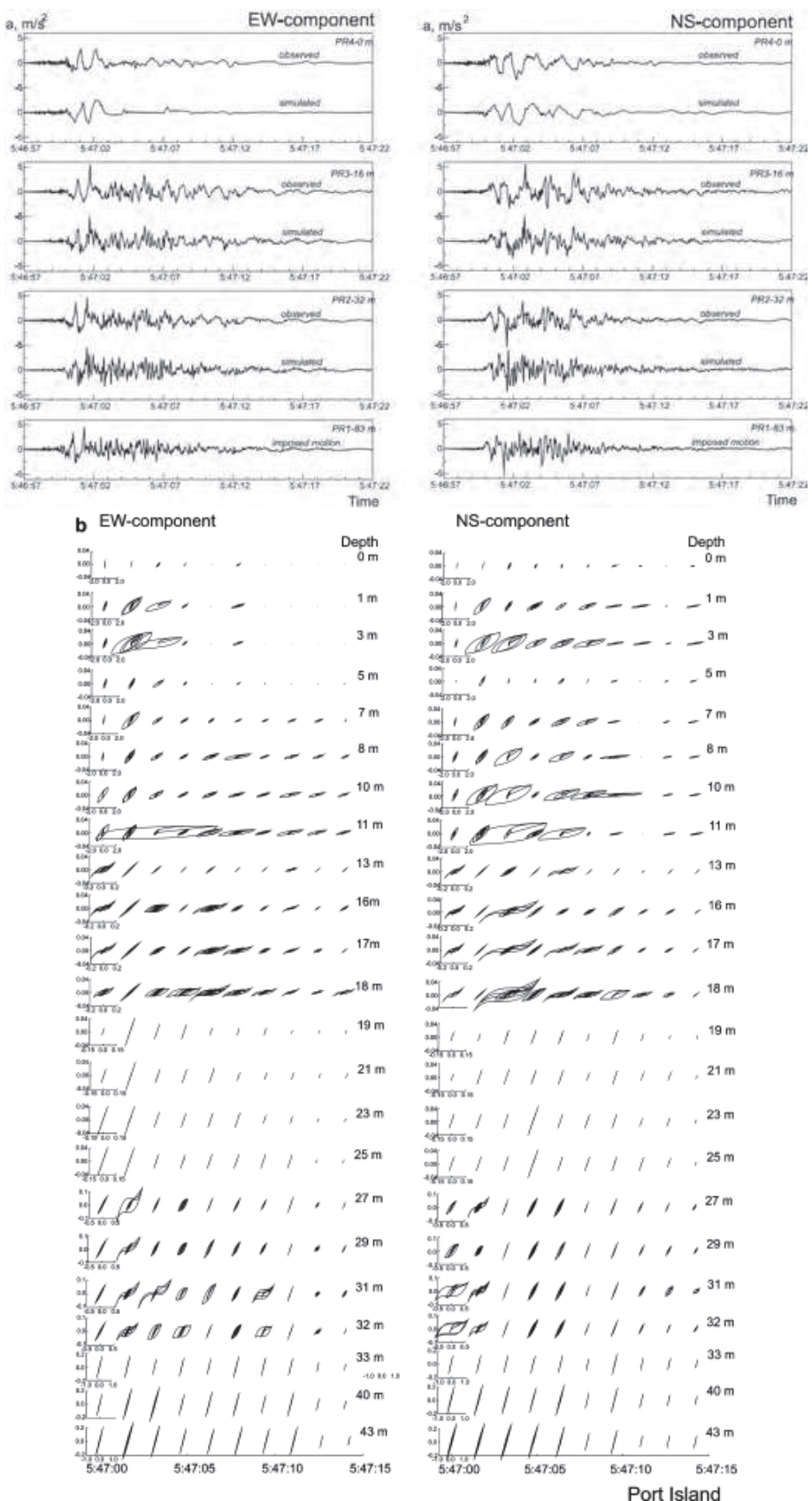

Fig. 2.3. The acceleration time history of the main shock in PI, observed and simulated (a), and the obtained stress-strain relations changing with time (b). The axes scales of the stressstrain relations are in relative units; the same for all time intervals at a given depth. 
depths 13-18 m and 27-32.5 m, the obtained stress-strain curves show a slight reduction and the following recovery of the shear modulus. Below $32.5 \mathrm{~m}$, no changes in the soil behavior are observed (Fig. 2.3b).

At SGK and TKS sites no liquefaction occurred, though sand boils observed after the quake around the TKS site indicate that liquefaction took place in the vicinities of this site. Maximum accelerations recorded at SGK site were also high (Fig. 2.4a), up to $650 \mathrm{Gal}$ on the surface for the EW-component.

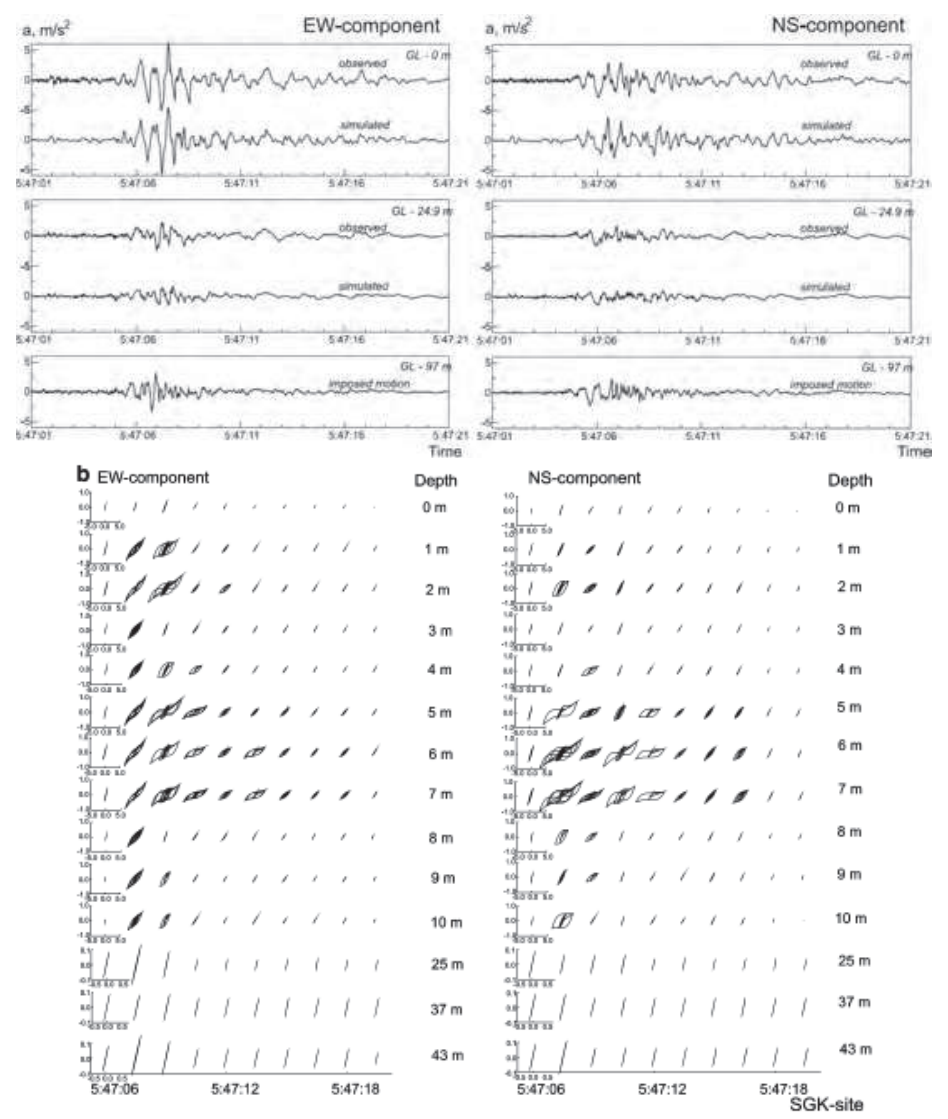

Fig. 2.4. The acceleration time history of the main shock in SGK site, observed and simulated (a), and the obtained stress-strain relations changing with time (b). The axes scales of the stress-strain relations are in relative units; the same for all time intervals at a given depth.

At this site, the soil behavior can be described by a relatively simple model: the soil profile is divided into two groups of layers, such as the near-surface alluvial layers (0-11 m), and the deeper layers (below $11 \mathrm{~m}$ ), which are mostly gravel and clays. High values of P-wave velocities in the upper layers indicate the presence of water (Fig. 2.2), therefore, curves of type (3) are appropriate for the upper layers. Curves of type (1) were used for the deeper layers. Figure 2.4 represents the observed and simulated accelerograms (a) and the obtained stress-strain relations (b) for SGK site. The behavior of the layers below $11 \mathrm{~m}$ is stationary, 
whereas the stress-strain relations describing the behavior of the upper layers change with time: slopes of the curves decrease, then increase again, indicating reduction and recovery of the shear modulus in the upper layers.

At TKS site, maximum recorded accelerations were about $200 \mathrm{Gal}$, and the soil profile is represented by a water-saturated reclaimed fill and an alluvial layer in the upper part (0-14 $\mathrm{m})$, and by gravel, clays, and sands in the deeper parts. Since the soil conditions are similar to that at SGK site, the choice of curves was also similar: curves of type (3) were selected for the upper $14 \mathrm{~m}$, and curves of type (1) were chosen for the deeper parts. The most intense movements took place in the layers below the level of the underground water, at depths 4-7 $\mathrm{m}$. At TKS site, the soil behavior in the upper layers changes with time similar to SGK site: we observe reduction and the following recovery of the shear modulus, whereas, the behavior of layers below $14 \mathrm{~m}$ is stationary.

The obtained stress-strain relations seem to represent a fairly good approximation to reality. On one hand, they show a good agreement between the observed and simulated data. On the other hand, they give a description of the process which is physically correct, i.e., the stress-strain relations obtained for Port Island show progressive liquefaction in the upper layers and a stable behavior in the deeper parts. Reduction and a following recovery of the shear modulus is obtained for the upper layers at SGK and TKS sites. Similarity of the stressstrain relations obtained for two horizontal components is an additional factor testifying to the validity of the solution. As shown above, the choice of the types of stress-strain relations in layers was physically justified. To check the possibility of different representations (i.e., vertical distributions of the stress-strain relations), calculations were performed several times for Port Island and SGK sites, with variations in the shapes of curves, however, every time similar distributions of the stress-strain relations in layers were obtained.

Numerical simulation of accelerograms of the Kobe earthquake at depths of locations of the recording devices has shown that, (1) at least within $\sim 8-10 \mathrm{~km}$ from the fault plane, the nonlinearity in the soil response was substantially higher than that stipulated by conventional computer programs of the nonlinear ground response analysis, and (2) stressstrain relations of different types, depending on the composition of soil layers, their saturation with water, and depth, describe the behavior of the layers. In particular, the behavior of sandy water-saturated or wet subsurface soils is described by stress-strain relations of "hard" type, declining to the stress axis at large strains. In such soils, amplification of large-amplitude oscillations occurs, which is related to the "hard-type" nonlinearity of the soil response, like at SGK site during the 1995 Kobe earthquake.

\section{Nonlinear behavior of soils revealed from the records of the 2000 Tottori (Japan) earthquake at stations of the Digital Strong Motion Network Kik-Net}

During the Kobe earthquake, the nonlinear soil behavior was identified at sites located within $\sim 16 \mathrm{~km}$ from the fault plane, and the content of nonlinear components in the soil response was estimated. It turned out to be rather high, up to $\sim 60 \%$ of the whole intensity of the response, at $\sim 2 \mathrm{~km}$ from the fault plane and about $10-15 \%$ of the intensity of the response at $\sim 16 \mathrm{~km}$ from the fault plane (Pavlenko \& Irikura, 2005). Such kind of analysis and estimations became possible because of the availability of vertical array records of the Kobe earthquake. Seismic vertical arrays usually contain two, three, or four threecomponent accelerometers, installed on the surface and at depths down to $\sim 100$ or $\sim 200 \mathrm{~m}$; one of the primary motivations for observations with borehole arrays is to understand nonlinear soil response. 
The Tottori earthquake occurred in the Tottori Prefecture of Japan at approximately 1:30 p.m. on October 6, 2000. The earthquake mechanism was a strike-slip fault, and the fault rupture plane surface was about $30 \mathrm{~km}$ wide by $10 \mathrm{~km}$ deep, nearly vertical. This earthquake was recorded by stations of the Kiban-Kyoshin Digital Strong-Motion Seismograph Network (Kik-Net) at 220 sites located at epicentral distances of 7 to $626 \mathrm{~km}$. It resembled the 1995 Kobe earthquake in its magnitude and focal depth and therefore represented a good opportunity to check the conclusions made based on records of the Kobe earthquake.

Acceleration records of the 2000 Tottori earthquake, provided by the Kik-Net stations, show a clear evidence of the nonlinearity of soil response at sites located in near-fault zones, such as evident differences in shapes and spectra of records on the surface and at depth, emphasizing low-frequency oscillations on the surface. In this paragraph, we analyze accelerograms of the 2000 Tottori earthquake (Fig. 3.1) and reconstruct stresses and strains, induced in soil layers at sites, where the nonlinear soil behavior was identified. We estimate reduction of the shear moduli of the soil layers, caused by the strong motion, and discuss transformations of spectra of seismic waves in the soil layers. The Kik-Net stations contain two accelerometers, installed on the surface and at a depth of $\sim 100$ or $\sim 200 \mathrm{~m}$. Simultaneous records of the two devices allow us to simulate the behavior of soil layers from the surface down to the location of the deep device. For data processing, we chose stations located within $\sim 80 \mathrm{~km}$ from the epicenter, where maximum recorded accelerations exceeded 100 Gal, assuming that at larger distances or at smaller accelerations the soil response is linear. The list of the studied Kik-Net stations with their epicentral distances, maximum recorded accelerations, and soil conditions is given in Table I.

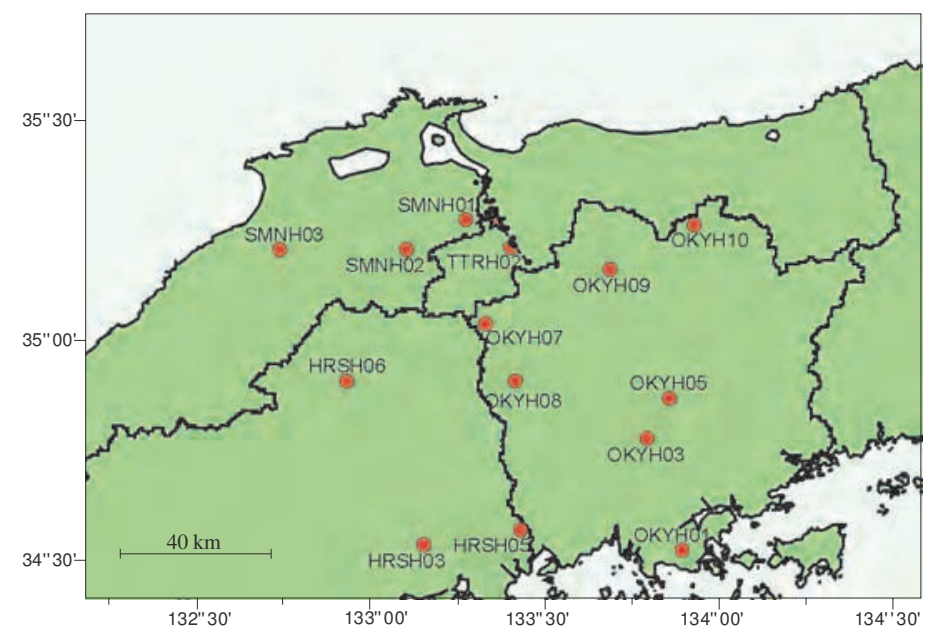

Fig. 3.1. Locations of the main shock of the 2000 Tottori earthquake and KiK-net stations in the vicinity of the epicenter (derived from the KiK-net website).

Nonlinear soil behavior was identified at five Kik-Net stations: TTRH02, SMNH01, HRSH06, SMNH03, and HRSH05 stations, located at $7 \mathrm{~km}, 8 \mathrm{~km}, 57 \mathrm{~km}, 57 \mathrm{~km}$, and $80 \mathrm{~km}$ from the epicenter, respectively. At other stations, listed in Table I, either the profiling data were absent, or the thickness of soft subsurface soil layers was less than $\sim 10 \mathrm{~m}$ and they were underlayed by dense rock, so that resonant phenomena predominated over nonlinear ones. 
The profiling data, such as, the composition of the soil layers, P- and S- wave velocities, are provided by the Kik-Net website. At TTRH02 station, the upper $10.5 \mathrm{~m}$ represent sand and gravel $\left(\mathrm{V}_{\mathrm{S}} \sim 210 \mathrm{~m} / \mathrm{s}\right)$; at $\mathrm{SMNH01}$ station, the upper $12 \mathrm{~m}$ are fill soil with sand, gravel, silt, and cobble stone $\left(\mathrm{V}_{\mathrm{S}} \sim 290 \mathrm{~m} / \mathrm{s}\right)$. At both stations below these layers down to $\sim 100 \mathrm{~m}$, granites, andesites, and basalts are identified with $V_{S}$ gradually increasing from $340 \mathrm{~m} / \mathrm{s}$ (at $10.5-20 \mathrm{~m}$ ) to $790 \mathrm{~m} / \mathrm{s}($ at $42-100 \mathrm{~m}$ ) at TTRH02 and from $550 \mathrm{~m} / \mathrm{s}$ (at $12-22 \mathrm{~m}$ ) to $2800 \mathrm{~m} / \mathrm{s}$ (at 54-100 m) at SMNH01. At HRSH06 station, the upper $6 \mathrm{~m}$ represent weathered mudstone $\left(\mathrm{V}_{\mathrm{S}} \sim 170 \mathrm{~m} / \mathrm{s}\right)$, below which mudstones, conglomerates, and granites are found with $\mathrm{V}_{\mathrm{S}}$ increasing from $270 \mathrm{~m} / \mathrm{s}$ (at 6-19 m) to $1650 \mathrm{~m} / \mathrm{s}$ (at 51-100 m). At SMNH03, the soil profile consists of fill soil, concrete, sand, and gravel with cobble stone $\left(V_{\mathrm{S}} \sim 240 \mathrm{~m} / \mathrm{s}\right)$ in the upper $7 \mathrm{~m}$ and mudstones, sandstones, and porphyrites below with $\mathrm{V}_{\mathrm{S}}$ increasing from $390 \mathrm{~m} / \mathrm{s}$ (at $7-14 \mathrm{~m}$ ) to $1300 \mathrm{~m} / \mathrm{s}$ (at 51-100 m). At HRSH05, the upper $7.5 \mathrm{~m}$ of surface soil, clay, sand, and gravel $\left(\mathrm{V}_{\mathrm{S}} \sim 280 \mathrm{~m} / \mathrm{s}\right)$ are underplayed by more dense layers of sand and gravel with cobble stone, sandy clays, slates, and diabases with $\mathrm{V}_{\mathrm{S}}$ increasing from $420 \mathrm{~m} / \mathrm{s}$ (at 7.5-32.5 $\mathrm{m})$ to $2390 \mathrm{~m} / \mathrm{s}$ (at $80-100 \mathrm{~m}$ ).

\begin{tabular}{|c|c|c|c|c|}
\hline Site code & Site name & Max acceleration & Epicentral distance & $\begin{array}{l}\text { Thickness of the soft } \\
\text { layer }\left(\mathrm{V}_{\mathrm{s}}<300 \mathrm{~m} / \mathrm{s}\right)\end{array}$ \\
\hline TTRH02 & HINO & $927.2 \mathrm{gal}$ & $7 \mathrm{~km}$ & $11 \mathrm{~m}$ \\
\hline SMNH01 & HAKUTA & $720.4 \mathrm{gal}$ & $8 \mathrm{~km}$ & $10 \mathrm{~m}$ \\
\hline SMNH02 & NITA & $564.0 \mathrm{gal}$ & $24 \mathrm{~km}$ & $0 \mathrm{~m}$ \\
\hline OKYH07 & SHINGOU & $179.7 \mathrm{gal}$ & $26 \mathrm{~km}$ & $0 \mathrm{~m}$ \\
\hline SMNH10 & MIHONOSEKI & $226.4 \mathrm{gal}$ & $31 \mathrm{~km}$ & no profiling data \\
\hline OKYH09 & YUBARA & $283.8 \mathrm{gal}$ & $32 \mathrm{~km}$ & $0 \mathrm{~m}$ \\
\hline TTRH04 & AKASAKI & $218.1 \mathrm{gal}$ & $33 \mathrm{~km}$ & no profiling data \\
\hline OKYH08 & TETSUTA & $238.5 \mathrm{gal}$ & $41 \mathrm{~km}$ & $0 \mathrm{~m}$ \\
\hline OKYH14 & HOKUBOU & $443.0 \mathrm{gal}$ & $45 \mathrm{~km}$ & no profiling data \\
\hline SMNH12 & YOSHIDA & $258.6 \mathrm{gal}$ & $46 \mathrm{~km}$ & no profiling data \\
\hline SMNH11 & HIRATA & $58.2 \mathrm{gal}$ & $52 \mathrm{~km}$ & no profiling data \\
\hline OKYH10 & KAMISAIBARA & $280.7 \mathrm{gal}$ & $53 \mathrm{~km}$ & $8 \mathrm{~m}$ \\
\hline HRSH06 & KUCHIWA & $240.3 \mathrm{gal}$ & $57 \mathrm{~km}$ & $18 \mathrm{~m}$ \\
\hline SMNH03 & SADA & $154.8 \mathrm{gal}$ & $57 \mathrm{~km}$ & $7 \mathrm{~m}$ \\
\hline OKYH05 & TAKEBE & 149.0 gal & $65 \mathrm{~km}$ & $4 \mathrm{~m}$ \\
\hline OKYH03 & OKAYAMA & 129.5 gal & 69 km & $7 \mathrm{~m}$ \\
\hline OKYH11 & SYOUOU & $139.1 \mathrm{gal}$ & 74 km & $9 \mathrm{~m}$ \\
\hline SMNH05 & HASUMI & $121.5 \mathrm{gal}$ & 79 km & $4 \mathrm{~m}$ \\
\hline HRSH05 & KANNABE & $131.0 \mathrm{gal}$ & $80 \mathrm{~km}$ & $7 \mathrm{~m}$ \\
\hline
\end{tabular}

Table 3.1. Maximum recorded accelerations, epicentral distances, and soil conditions at the Kik-Net stations located in near-fault zones of the 2000 Tottori earthquake (data derived from the Kik-Net website).

For calculations, the soil profiles were divided into two groups of layers, according to the profiling data. At all stations the groups of upper soft layers were distinguished $(10.5 \mathrm{~m}$ at TTRH02, $12 \mathrm{~m}$ at SMNH01, $6 \mathrm{~m}$ at HRSH06, $7 \mathrm{~m}$ at SMNH03, and $7.5 \mathrm{~m}$ at HRSH05), and "hard-type" stress-strain relations were selected to describe the behavior of these layers. To describe the behavior of deeper layers at all the stations, we used stress-strain relations obtained in laboratory experiments by Hardin \& Drnevich (1972). To account for temporal 
changes in the soil behavior, successive 1.5-second time intervals were analyzed; calculations were performed successively, interval by interval. Since the profiling data provided by the Kik-Net website contain only the composition of the soil and P- and Swave velocities in the layers, we estimated other parameters used in calculations, such as shear stress in failure, $\tau_{\max }$, density, and damping in the soil layers. Also we defined more exactly S- wave velocity profiles at the closest to the fault plane stations TTRH02 and SMNH01. Density and damping were estimated based on the soil composition. To estimate other profiling parameters, we performed inversion using the genetic algorithm. For the inversion, we used twenty aftershocks of the Tottori earthquake recorded by the two stations during one month after the main shock. Intervals defining allowed values of Swave velocities $V_{S}$ in the soil layers (input data in the inversion problem) included $V_{S}$ values provided by the Kik-Net website; limiting estimates of $\tau_{\max }$ were based on empirical relationships, accounting for the composition of a soil layer, S- wave velocity and preexisting stress in the layer. For each model (combination of $V_{S}$ and $\tau_{\max }$ profiling values), we calculated the propagation of the aftershock waves in the soil layers; the behavior of the layers was described by the stress-strain relation obtained by Hardin \& Drnevich (1972).

All the models were evaluated by the summary deviations of the simulated accelerograms from the recorded ones. The deviations were calculated as sums of the mean square "pointby-point" deviations and the differences of the mean intensities of the simulated and recorded accelerograms. The "best" model was produced after crossing of fifty initial models during about five hundred generations. Based on the obtained profiling data, stresses and strains induced in the soil layers at the five stations during the main shock of the earthquake were estimated. The obtained stresses and strains were used to trace changes in the shear moduli in the soil layers. Estimated stresses and strains at depths of $0-100 \mathrm{~m}$ or $0-200 \mathrm{~m}$, changing with time during the strong motion for TTRH02 and SMNH01 stations are shown in (Figs 3.2 and 3.3).

A rather good agreement was obtained between the simulated and observed accelerograms for all the stations, though the agreement is worse than that achieved for SGK and TKS sites in simulating accelerograms of the 1995 Kobe earthquake. Evidently, the accuracy of simulation sufficiently depends on the available information on the parameters of the soil profiles. However, the applied method of simulation allows some correction of the soil parameters. Stress-strain relations used in calculations are defined in their normalized form in the manner proposed by Hardin \& Drnevich (1972): stress is normalized by multiplying by $1 / \tau_{\max }$, and strain is normalized by multiplying by $\mathrm{G}_{\max } / \tau_{\max }$. During the calculations, stress-strain relations are selected, which satisfy the prescribed (probably, with some error) values of $G_{\max }$ and $\tau_{\max }$ to simulate oscillations on the surface close to the observed ones. At the same time, the result, i.e., vertical distributions of stresses and strains in the soil layers, is expressed in absolute stress and strain units (Figs 3.2, 3.3); this decreases its dependence on the selected $G_{\max }$ and $\tau_{\max }$, and allows us to make conclusions about the soil behavior.

At the closest to the fault plane stations TTRH02 and SMNH01, the soil response was substantially nonlinear, as seen from Figs 3.2 and 3.3. At these stations, the behavior of the upper soil layers during the earthquake can not be described by a single stress-strain relation; an agreement between the observations and simulations can only be obtained if we describe the behavior of the upper layers by different stress-strain relations at different time intervals. Thus, strong ground motion changes rheological properties of the upper soil layers in near-fault zones. 


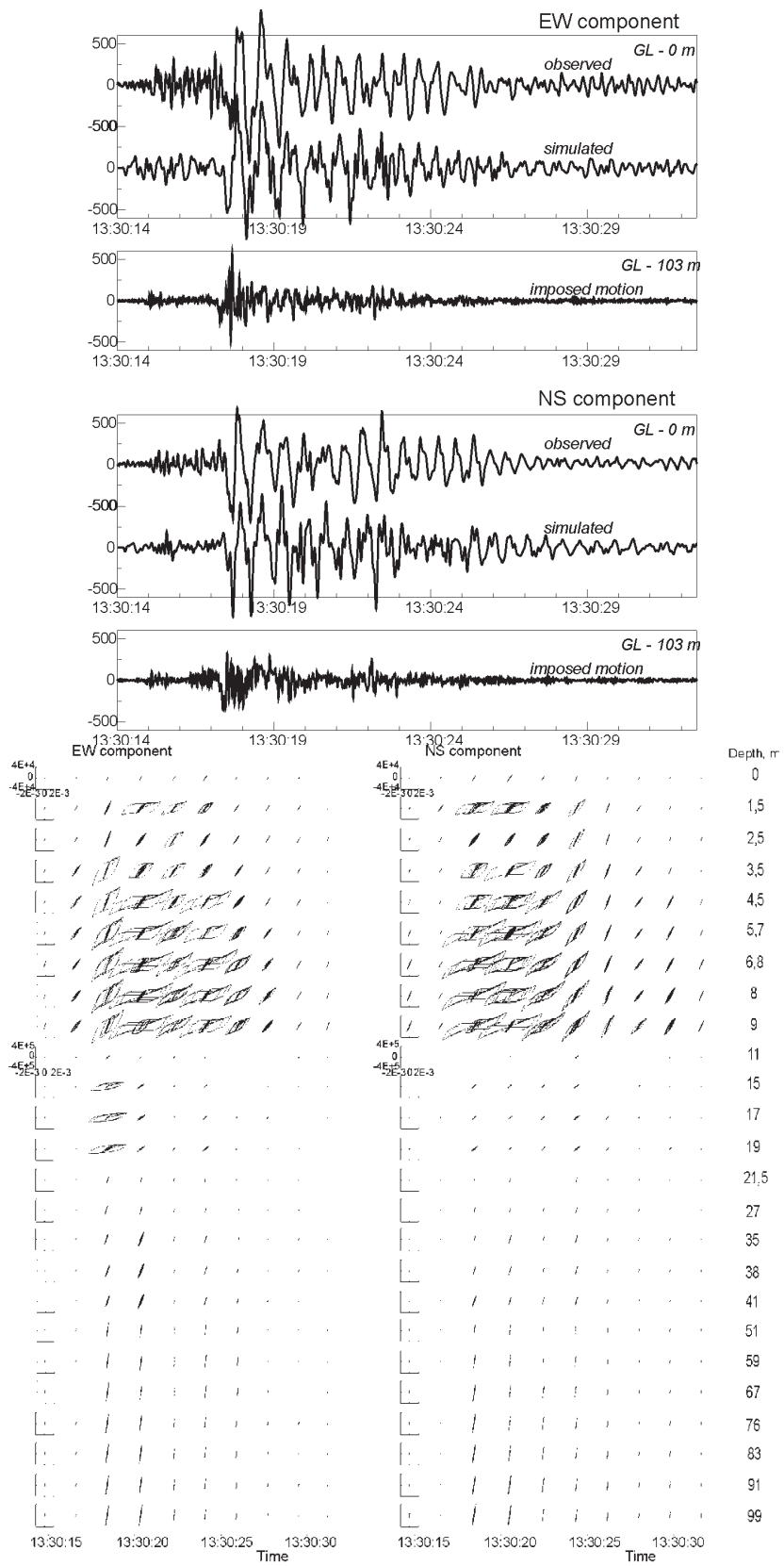

Fig. 3.2. The acceleration time histories of the main shock of the Tottori earthquake, observed and simulated, and estimated stress-strain relations in the soil layers, changing with time during the strong motion, at the TTRH02 station (stresses are given in $\mathrm{kPa}$, strains - in strains, the same scales for depths $0-10 \mathrm{~m}$ and $11-100 \mathrm{~m}$ ). 


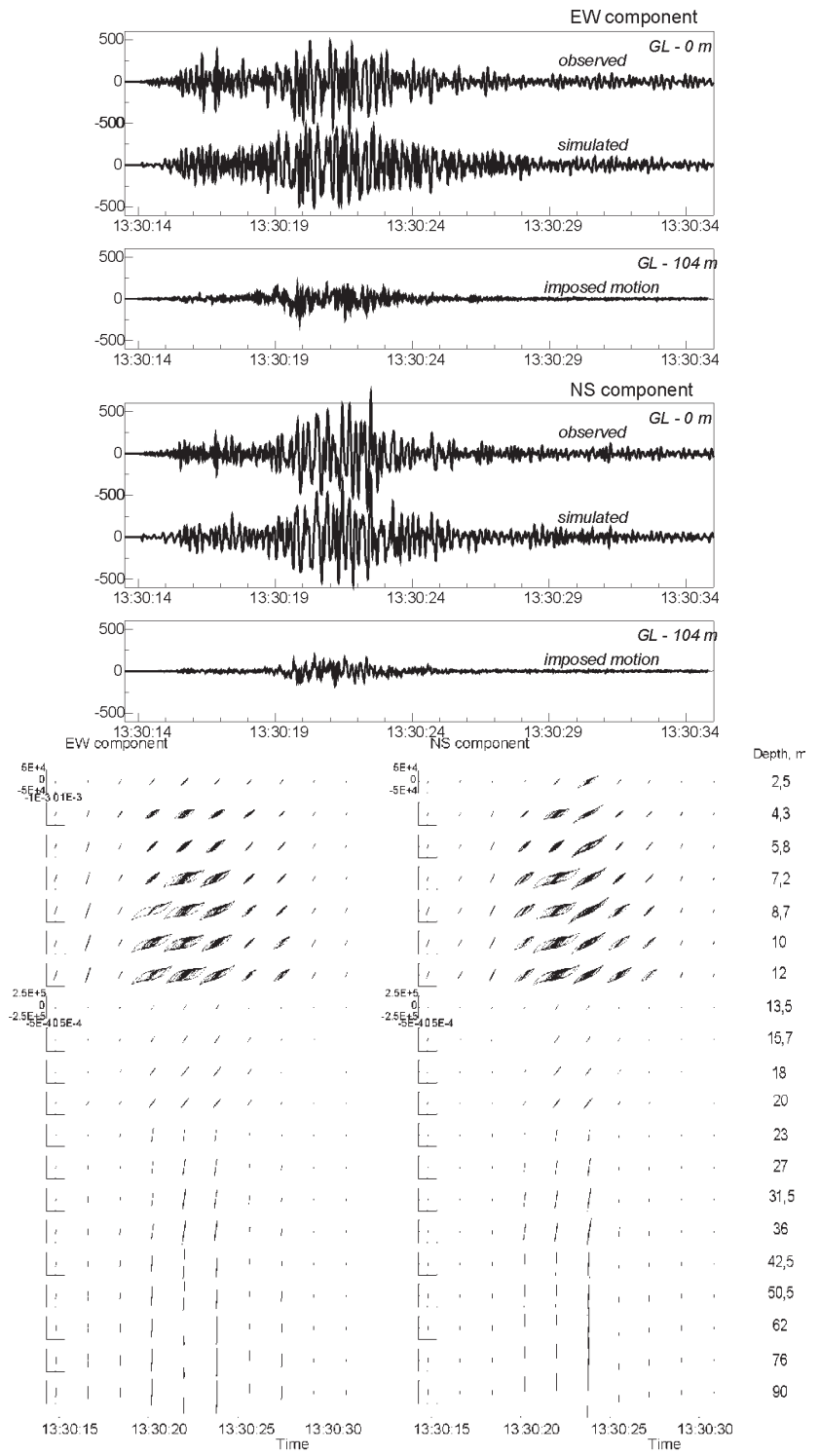

Fig. 3.3. Same as Figure 3.2 for the SMNH01 station (stresses are given in $\mathrm{kPa}$, strains - in strains, the same scales for depths $0-12 \mathrm{~m}$ and $13-100 \mathrm{~m}$ ).

Strains induced by the strong motion achieve $0.6 \%$ in the upper $10.5 \mathrm{~m}$ at TTRH02 station and $0.3 \%$ in the upper $12 \mathrm{~m}$ at SMNH01 station. At both stations resonant oscillations in the upper soil layers are observed; maximum stresses are as high as $\sim 0.6$ bars in the upper 10-12 $\mathrm{m}$ and increase with depth up to $\sim 5$ bars at 50-100 $\mathrm{m}$, whereas strains decrease with depth. The shapes of the stress-strain curves in the upper soil layers reveal pore pressure development during the strong motion (Figs 3.2 and 3.3). 
At stations HRSH06, SMNH03, and HRSH05, located at epicentral distances of $57 \mathrm{~km}$ and more, the behavior of the upper soil layers is described by the same stress-strain relation at all time intervals, rheological properties of the soil are not changed. During the 1995 Kobe earthquake, changes of the rheological properties of the upper soil layers were detected at Port Island and SGK sites, located within $\sim 6 \mathrm{~km}$ from the fault plane. Thus, records of two earthquakes with magnitudes $\mathrm{M}_{\mathrm{w}} \sim 6.7-6.8$ and focal depths less than $\sim 30 \mathrm{~km}$ allow a rough estimation of the area where rheological properties of the upper soil layers change, as $\sim 7-8$ $\mathrm{km}$, or $\sim 1 / 4$ of the length of the fault. Stresses and strains in the soil layers at these stations are substantially lower than at TTRH02 and SMNH01: up to 0.12 bars and $0.05 \%$ in the upper 5-8 m; stresses increase up to $\sim 0.5$ bars at 50-100 m.

The estimated stresses and strains, changing with time during the strong motion, were used to trace changes in the shear moduli of the soil layers. As seen from Figs $3.2-3.3$, these changes are observed in the upper 9-12 $\mathrm{m}$ of the soil profiles at the closest to the fault plane stations. The behavior of the deeper layers at these stations and the behavior of all the layers at remote stations HRSH06, SMNH03, and HRSH05 were stable. Shear moduli were calculated as slopes of stress-strain curves averaged over the groups of upper layers and over oscillations within each time interval during the strong motion. At TTRH02 and SMNH01 stations, the reduction of the shear moduli in the upper layers achieved $\sim 60 \%$ of their initial values, at HRSH06 station the reduction of the shear moduli did not exceed $15 \%$ of the initial value, though scattering does not allow accurate estimation, and at SMNH03 and HRSH05 stations it was negligible.

Though scattering of the obtained estimates of shear moduli reduction indicate some inaccuracy in our simulations, we can see from our results a total recovering of the shear modulus at TTRH02 station and its almost total recovering at SMNH01 station. Note that the recovering starts immediately following the decrease of the intensity of the strong motion, which testifies to a high permeability of the upper soil layers as composed of noncohesive soils: sands, gravels, silts with cobble stones. Similar shear modulus behavior was observed at SGK and TKS sites during the 1995 Kobe earthquake (Pavlenko \& Irikura, 2002).

Note a significant amplification of low-frequency oscillations on the surface at TTRH02 station, which is due to the "hard-type" nonlinearity of the soil response, as seen from Fig. 3.2. A similar tendency is seen in records of SMNH01 station. At other stations, the thickness of the soft soil layer is rather small, and resonance effects predominate in oscillations on the surface. As a result, transformations of spectra caused by the nonlinearity of the soil response are virtually insignificant.

As known, nonlinearity of the soil response induces changes in spectra of seismic waves propagating in the soil layers: the energy of the waves is redistributed over the spectral bands, because of mutual interactions of spectral components of the propagating waves. Low-frequency components are amplified, spectral peaks and spectral gaps smooth, and spectra of oscillations on the surface tend to take the form $E(f) \sim f-k$. This spectral shape can be achieved in cases of strong nonlinearity (intense seismic waves and/or thick soft soil layers), whereas in cases of weak nonlinearity, we only see the tendencies of these spectral transformations. These tendencies are clearly seen in spectra of TTRH02 station. At other stations, however, resonance phenomena prevail, and spectral changes, induced by the soil nonlinearity, are inconspicuous. 


\section{Characteristics of soil response in near-fault zones during the 1999 Chi- Chi, Taiwan, earthquake}

The Chi-Chi earthquake ( $\mathrm{Mw}=7.6)$ that occurred in central Taiwan on September 21, 1999 was recorded by more than 400 strong motion devices island wide. The majority of nearfault records were obtained at soil sites, and at present they apparently represent the most complete database allowing a study of soil behavior during a strong earthquake in nearfault zones at various distances from the fault.

In (Pavlenko \& Wen, 2008) we simulated acceleration time histories of the Chi-Chi earthquake at rock and soil sites and constructed models of the behavior of upper $\sim 80 \mathrm{~m}$ of soil at 31 soil sites located within $\sim 50 \mathrm{~km}$ from the fault. To construct models of soil behavior, we used a method similar to that developed for the estimation of soil behavior based on vertical array records (Pavlenko \& Irikura, 2003; 2006). As input for soil layers, we used acceleration time histories of the Chi-Chi earthquake, simulated by stochastic finitefault modeling with a slip distribution over the fault plane obtained by Chi et al. (2001). First, we simulated the acceleration time histories of the Chi-Chi earthquake at 18 rock sites, and comparing them with the observed ones, calibrated the calculation program, i.e., found input parameters for the stochastic simulation, such as, parameters of radiation of seismic waves from the source and parameters of their propagation: geometrical spreading, $Q(f)$, kappa operator describing additional attenuation of the spectra, parameters defining the shape of the time window and some others. The earthquake source $(119 \mathrm{~km}$ by $35 \mathrm{~km})$ was represented as a set of 85 subfaults of $7 \mathrm{~km}$ by $7 \mathrm{~km}$. At the second stage, we simulated acceleration time histories at soil sites, at the bottoms of soil layers. These signals were used as "inputs" to soil layers, i.e., prescribed motion at the base of soil columns (that is, we assumed infinity rigidity in the underlying medium). The technique and the constructed models of soil behavior at 31 soil sites are described in detail in (Pavlenko \& Wen, 2008). The models represent vertical distributions of hysteretic relations of stresses and strains, induced in the upper tens of meters of soil and changing in time during the strong motion.

Models of soil behavior are constructed for 31 soil sites located at various distances from the fault plane within a wide range of azimuthal directions, and they allow us to obtain a general representation of soil behavior during the Chi-Chi earthquake. With these models, we can investigate some regularities in soil behavior during a strong earthquake at various distances from the fault plane.

In this paragraph, the constructed models of soil behavior are applied to estimate parameters, characterizing soil response during the Chi-Chi earthquake, such as, amplification of seismic waves by soil layers, stresses and strains induced by the strong motion in soil layers at different depths, reduction of shear moduli in soil layers due to strong motion, and nonlinear components of soil response. The distributions of these parameters around the fault plane are analyzed. Information on the soil sites, such as, the distances to the fault plane and site classification according to (Lee et al., 2001), as well as estimated parameters of soil response, are given in Figure 4.1 and in Table 4.1.

Maximum and average (averaged over the duration of the strong motion) stresses and strains induced by the strong motion in soil layers were estimated. To obtain these estimates, at each site, for each soil layer, maximum (during the strong motion) stresses and strains were found; to find their average estimates, absolute values of "limiting" (for loading and unloading cycles) stresses and strains corresponding to final points of loading and unloading on the hysteretic curves were averaged for each site and for each soil layer; then, 
averaging was performed over two horizontal components, NS and EW. Average values of stresses and strains were estimated for the upper $30 \mathrm{~m}$ of soil most representative from the viewpoint of engineering seismology.

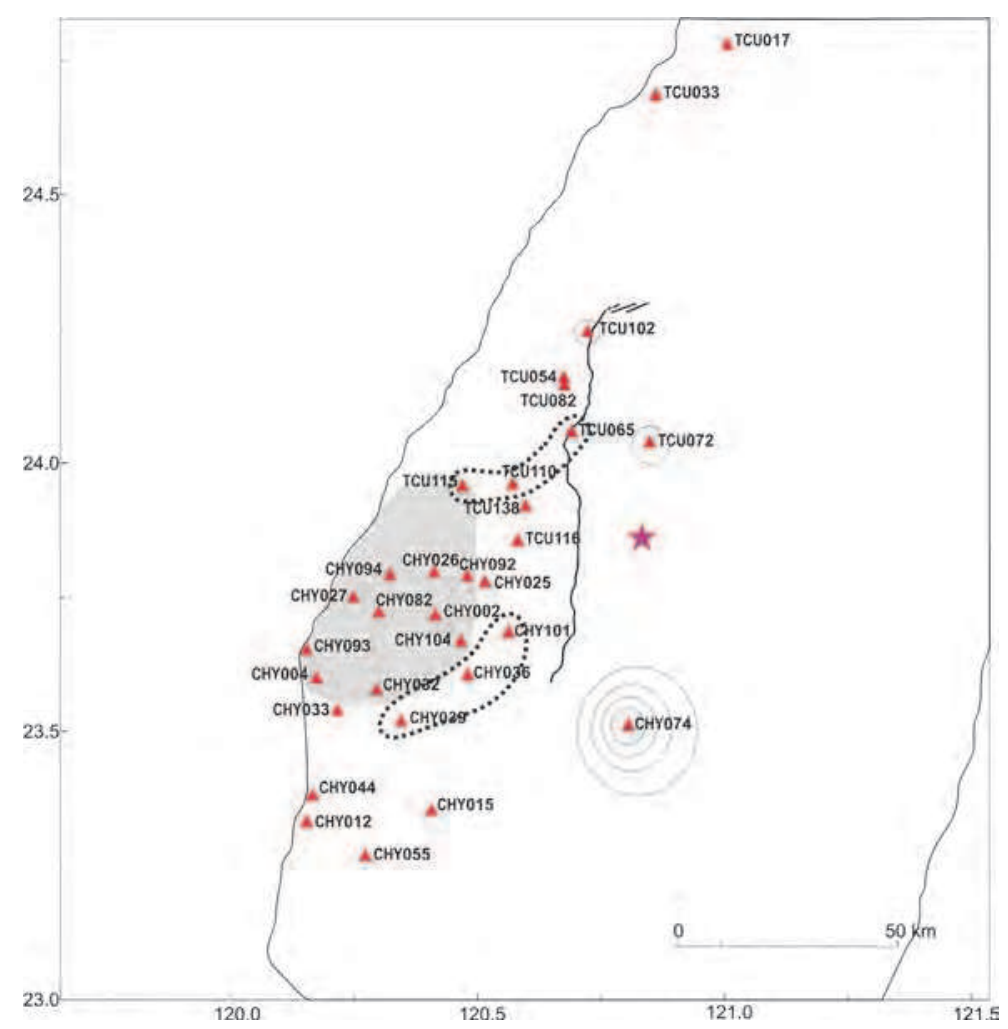

Fig. 4.1. Locations of the studied soil sites around the fault plane of the Chi-Chi earthquake. Dotted lines indicate areas showing signs of soil liquefaction; the area of basin-induced surface waves is marked by gray color.

Shear moduli reduction values were assessed for soil layers within the upper $30 \mathrm{~m}$ in the following way. For each site, average shear moduli were calculated as the ratios of stresses and strains averaged in time (over the strong motion duration), in depth (over the upper 30 $\mathrm{m})$, and over two horizontal components; stresses and strains were taken as their absolute values corresponding to final points of loading and unloading cycles of the hysteretic curves. Shear moduli reduction was calculated as the difference between maximum values of shear moduli, calculated within small time intervals at the beginning parts of the strong motion records, and their average values, normalized by the average values and expressed in percent.

To estimate the contents of nonlinear components in soil response, methods of nonlinear system identification and the white-noise approach (Marmarelis \& Marmarelis, 1978) were applied. Application of these methods to seismic data analysis is described in (Pavlenko, 2001; Pavlenko \& Irikura, 2005). 


\begin{tabular}{|c|c|c|c|c|c|c|c|c|c|}
\hline $\begin{array}{l}\text { Station } \\
\text { Code }\end{array}$ & $r, \mathbf{k m}$ & $\begin{array}{l}V_{s-30,} \\
\mathrm{~m} / \mathrm{s}\end{array}$ & $F_{a}$ & $F_{v}$ & $\mathrm{\tau}_{30}, \mathrm{~Pa}$ & $\gamma_{30}, 10^{-5}$ & $\begin{array}{c}\Delta G / G_{\max -30} \\
\%\end{array}$ & $\begin{array}{c}N l, \\
\%\end{array}$ & \begin{tabular}{|c} 
Site Class \\
(Lee et al., \\
2001)
\end{tabular} \\
\hline CHY101 & 1.9 & 260 & 1.5 & 2.0 & 1817 & 18.0 & 81 & 75 & $\mathrm{D}$ \\
\hline TCU110 & 2.4 & 207 & 0.7 & 2.9 & 1013 & 32.0 & 46 & 57 & $\mathrm{E}$ \\
\hline TCU116 & 3.4 & 483 & 1.0 & 1.8 & 852 & 0.3 & 32 & 16 & $E$ \\
\hline TCU138 & 3.8 & 605 & 1.1 & 1.6 & 2140 & 0.54 & 10 & 24 & $\mathrm{D}$ \\
\hline TCU082 & 5.7 & 478 & 1.0 & 1.7 & 1162 & 0.3 & 15 & 15 & $\mathrm{D}$ \\
\hline CHY025 & 5.9 & 277 & 1.2 & 2.7 & 1487 & 11.5 & 41 & 62 & $\mathrm{E}$ \\
\hline TCU054 & 6.1 & 454 & 1.1 & 1.7 & 1494 & 0.8 & 21 & 11 & $\mathrm{D}$ \\
\hline TCU065 & 6.9 & 300 & 2.5 & 2.9 & 1677 & 9.3 & 63 & 54 & $\mathrm{D}$ \\
\hline CHY036 & 7.5 & 282 & 2.4 & 2.1 & 1995 & 9.6 & 73 & 61 & $\mathrm{D}$ \\
\hline TCU102 & 7.8 & 735 & 1.4 & 2.2 & 2325 & 3.4 & 51 & 56 & $\mathrm{D}$ \\
\hline CHY092 & 9.5 & 260 & 1.3 & 2.5 & 440 & 1.2 & 37 & 11 & $\mathrm{E}$ \\
\hline CHY104 & 9.5 & 225 & 2.2 & 2.9 & 1435 & 5.7 & 13 & 28 & $\mathrm{E}$ \\
\hline TCU115 & 11.4 & 190 & 1.4 & 3.1 & 654 & 17.0 & 34 & 50 & $\mathrm{E}$ \\
\hline CHY074 & 12.8 & 546 & 1.6 & 2.1 & 1824 & 3.5 & 44 & 25 & C \\
\hline TCU072 & 14.9 & 563 & 2.7 & 2.1 & 3481 & 6.2 & 37 & 48 & $\mathrm{D}$ \\
\hline CHY002 & 15.0 & 231 & 1.9 & 2.6 & 420 & 0.7 & 16 & 28 & $\mathrm{E}$ \\
\hline CHY026 & 16.1 & 226 & 1.2 & 2.0 & 530 & 8.0 & 22 & 33 & $\mathrm{E}$ \\
\hline TCU033 & 16.9 & 448 & 2.3 & 1.9 & 1642 & 0.5 & 12 & 22 & $\mathrm{D}$ \\
\hline CHY039 & 20.8 & 198 & 2.0 & 2.2 & 450 & 5.8 & 86 & 27 & $\mathrm{E}$ \\
\hline CHY094 & 24.9 & 227 & 1.6 & 2.7 & 1048 & 4.1 & 9 & 16 & $\mathrm{E}$ \\
\hline CHY032 & 25.6 & 202 & 3.1 & 3.2 & 780 & 2.9 & 9 & 33 & $\mathrm{E}$ \\
\hline CHY015 & 25.9 & 234 & 2.2 & 2.6 & 361 & 1.0 & 19 & 31 & $\mathrm{D}$ \\
\hline CHY082 & 26.6 & 209 & 2.2 & 3.0 & 211 & 0.8 & 13 & 25 & $E$ \\
\hline TCU017 & 29.7 & 601 & 2.2 & 2.3 & 227 & 0.2 & 28 & 8 & $?$ \\
\hline CHY027 & 32.1 & 221 & 3.9 & 3.4 & 645 & 4.9 & 13 & 24 & $\mathrm{E}$ \\
\hline CHY033 & 33.6 & 194 & 3.0 & 3.6 & 970 & 5.3 & 7 & 13 & $\mathrm{E}$ \\
\hline CHY004 & 38.2 & 279 & 2.8 & 3.0 & 1342 & 3.5 & 7 & 11 & $\mathrm{E}$ \\
\hline CHY093 & 41.2 & 199 & 2.8 & 3.4 & 1145 & 4.7 & 5 & 11 & $\mathrm{E}$ \\
\hline CHY055 & 41.5 & 240 & 3.7 & 3.0 & 1234 & 3.8 & 5 & 12 & $\mathrm{E}$ \\
\hline CHY044 & 43.0 & 193 & 3.0 & 2.9 & 576 & 2.2 & 5 & 30 & $\mathrm{E}$ \\
\hline CHY012 & 46.6 & 202 & 3.5 & 2.8 & 276 & 1.0 & 2 & 28 & $\mathrm{E}$ \\
\hline
\end{tabular}

Table 4.1. Characteristics of soil response at 31 soil sites during the 1999 Chi-Chi earthquake

In this paragraph, the dependence of the described above parameters of soil response during the Chi-Chi earthquake on the distance from the fault plane is analyzed. All the studied soil sites are located in near-fault zones, and their distances from the fault plane are comparable with the fault length. Later on distance from the fault $r$ designates the shortest distance of a site from the fault plane.

As seen from Table 4.1, the majority of sites (22 sites) possess soft soils in the upper $30 \mathrm{~m}: \mathrm{V}_{\mathrm{s}-}$ 30 is less than $300 \mathrm{~m} / \mathrm{s}$, whereas at other 9 sites possessing denser subsurface soils $V_{\mathrm{s}-30}$ varies within $448-735 \mathrm{~m} / \mathrm{s}$. So in many cases it was found reasonable to consider separately these two groups of sites, such as, sites with "softer" subsurface soils $\left(\mathrm{V}_{\mathrm{s}-30} \leq 300 \mathrm{~m} / \mathrm{s}\right)$ and sites 
with "harder" subsurface soils $\left(\mathrm{V}_{\mathrm{s}-30} \geq 450 \mathrm{~m} / \mathrm{s}\right)$. At the same time, the whole number of the studied sites is not large and virtually all of them are located in valleys to the west of the fault, so that further division of them into smaller groups considering the age and composition of soil layers is not reasonable.

\subsection{Amplification of seismic waves in subsurface soils in near-fault zones during the Chi-Chi earthquake}

The constructed models of soil behavior allowed a rather detailed study of amplification of seismic waves by subsurface soils during strong ground motion. Amplification factors were estimated for acceleration and velocity ( $\mathrm{Fa}$ and $\mathrm{Fv}$ ); the results are presented in Figure 4.2 and in Table 4.1.
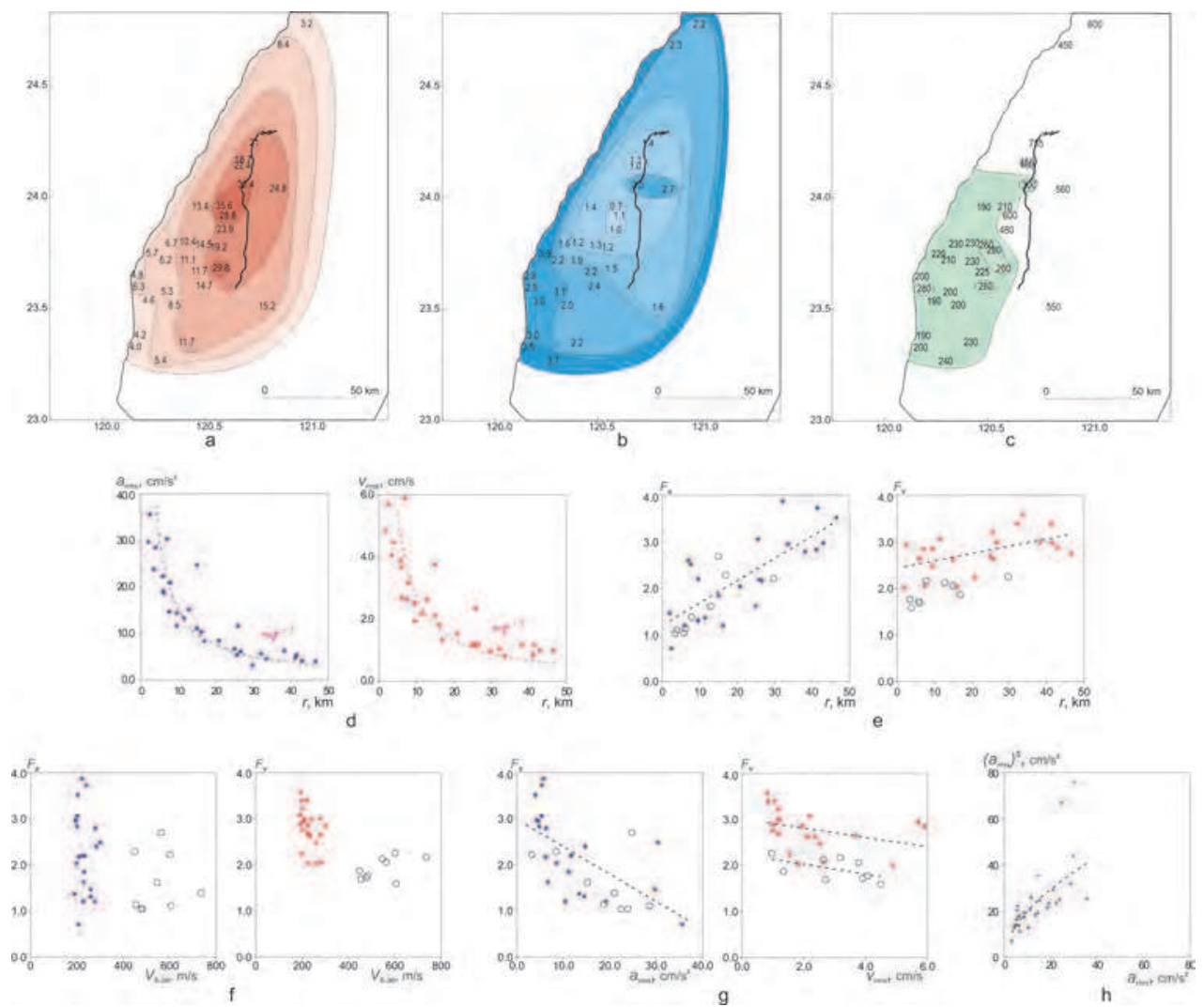

Fig. 4.2. Upper row: distribution around the fault plane of (a) - "input" motion to soil layers (rms accelerations at the bottoms of soil layers) $\mathrm{a}_{\mathrm{rms}}$ (b) - factors of amplification of seismic waves by soil layers for acceleration $F_{a}$ (c) - average $S$-wave velocities in the upper $30 \mathrm{~m} \mathrm{~V}_{\mathrm{S}-30}$. Lower row: (d) - "input" motion to soil layers $\mathrm{a}_{\mathrm{rms}}$ (e) - amplification factors for acceleration and velocity $F_{a}$ and $F_{v}$ as functions of the distance from the fault; (f), the dependencies of the obtained amplification factors on the level of "input" motion to soil layers (f), on $\mathrm{V}_{\mathrm{s}-30}(\mathrm{~g})$, and the dependency of rms accelerations on the surfaces $\left(\mathrm{a}_{\mathrm{rms}}\right) \mathrm{s}$ on rms accelerations at the bottoms of soil layers $\mathrm{a}_{\mathrm{rms}}$. 
The obtained results allow us to analyze the influence of various factors on the values of amplification of seismic waves by soil layers. Values of $a_{r m s}$ and $v_{r m s}$ decrease with increasing distance from the fault plane as $\sim \mathrm{r}^{-1}$ (Fig. 4.2d), which corresponds to theoretical decrease of amplitudes due to geometrical spreading. Amplification factors Fa and Fv are greater than 1 and smaller than 4 for virtually all the sites (Fig. 4.2b, e-g; Table 4.1). As seen from the figures, amplification increases with distance (Fig. 4.2 d), i.e., with decreasing amplitudes of "inputs" to soil layers, $a_{\text {rms, }}$ which is more clear for acceleration than for velocity. Linear functions can be used as approximating ones, however, scattering of the obtained estimates around linear regression lines is rather large, and it can be due to different factors.

As known, three main mechanisms of seismic wave transformation in subsurface soils are: (1) transition of seismic waves to upper soil layers with (usually) smaller values of $\mathrm{V}_{\mathrm{s}-30}$ and density, $\rho$, leading to amplification of seismic oscillations according to energy conservation law, (2) resonant phenomena the upper softer soil layers also leading to amplification, (3) nonlinearity of soil response, often leading to de-amplification of seismic oscillations. To evaluate the influence of different mechanisms on amplification of seismic waves in soil layers during the Chi-Chi earthquake, let's consider separately sites with "softer" and "harder" subsurface soils (in Fig. 4.2e-g they are shown by points and circles, respectively). As seen from the figure, amplification factors for acceleration, Fa, at "softer" and "harder" soil sites are close to each other, and can be approximated by the same function of the distance from the fault (or of the level of "input" motion), whereas, amplification factors for velocity, Fv, are substantially smaller at "harder" subsurface soils than at "softer" soils. This is clearly seen from Fig. $4.2 \mathrm{f}$ and agrees with seismological observations that "peak ground velocity and displacement show higher amplifications for soil sites than for rock sites (in our case, softer soil sites and harder soil sites), while peak ground acceleration is roughly independent of the site classification" (Aki \& Irikura, 1991) (that is, does not show higher amplification at soft soil sites).

The obtained results are in a good agreement with the dependencies of amplification factors on the intensity of ground motion and on average S-wave velocities in upper $30 \mathrm{~m}$ of soil described in (Stewart et al., 2001). The authors discuss general regularities of reduction of amplification factors with increasing $\mathrm{V}_{\mathrm{s}-30}$ or reference motion amplitude, obtained by various researchers for various strong earthquakes. Preliminary data on the 1999 Chi-Chi earthquake, obtained by Stewart et al., are also in agreement with the results of this work (Fig. 4.2g).

The observed dependencies of amplification factors on the level of "input" motion to soil layers is evidently due to the influence of nonlinearity of soil response, which is higher at the closest to the fault sites. At rather large distances from the fault $(\sim 40-50 \mathrm{~km})$, amplification factors Fa and Fv are close to each other (Fig. 4.2e), whereas at small distances, nonlinearity of soil response substantially decreases amplification for acceleration and, to a lesser extent, for velocity. This can be due to nonlinear transformations of seismic waves propagating in soil layers: their spectra tend to take the form $E(f) \sim f-n$, when the high- and medium-frequency spectral components are decreased and the low-frequency components remain virtually at the same level. Obviously, the effect is stronger for accelerations than for velocities and displacements.

In (Pavlenko \& Wen, 2008), it was concluded that at the majority of soil sites, soil behavior during the Chi-Chi earthquake was defined by resonant oscillations induced in soil layers (in the upper $40-60 \mathrm{~m}$ ) during strong motion and by nonlinearity of soil response. 
At near-fault sites, subsurface water-saturated sandy soils possess hard-type nonlinearity, where de-amplification of seismic oscillations due to nonlinear damping can be rather small, because: (1) stresses in soil layers rapidly increase at large strains (especially, in near-fault zones) due to pore-pressure built-up (and therefore, accelerations also increase); (2) nonlinear damping (which is proportional to areas within hysteretic curves) in can be rather small, as at TCU065 site, for example (Pavlenko \& Wen, 2008). As a consequence, in nearfault zones in sandy water-saturated soils possessing hard-type nonlinearity, deamplification of seismic oscillations due to nonlinearity often can not compensate their amplification stipulated by other two (linear) mechanisms; as a whole, we observe amplification of oscillations on the surface. This is clearly seen, for example, in vertical array records of the 1995 Kobe earthquake at SGK site: in the upper $\sim 11 \mathrm{~m}$ of sandy soils possessing hard-type nonlinearity seismic oscillations were noticeably amplified, peak accelerations increased from $0.2-0.3 \mathrm{~g}$ at depths of $\sim 25 \mathrm{~m}$ and $100 \mathrm{~m}$ up to $\sim 0.7 \mathrm{~g}$ on the surface. At the same time at Port Island site, liquefied surface soils possessing soft-type nonlinearity substantially de-amplified seismic oscillations, especially their high-frequency components; peak accelerations at $83 \mathrm{~m}, 32 \mathrm{~m}, 16 \mathrm{~m}$, and on the surface were almost similar, 0.4-0.5 g (Pavlenko \& Irikura, 2003).

Thus, amplification factors can be rather large even in cases of strong nonlinearity (at high levels of "input" motion, in near-fault zones) at sites possessing hard-type nonlinearity of subsurface soils, which is clearly seen in Fig. 4.2b: at TCU065 and TCU072 sites located very closely to the fault plane, amplification factors are rather high, $\mathrm{Fa} \sim 2.5-2.7$.

Fig. $4.2 \mathrm{~h}$ shows the obtained estimates of rms accelerations on the surfaces of soil, $\left(\mathrm{a}_{\mathrm{rms}}\right)_{\mathrm{S}}$, versus estimates of rms accelerations at the bottoms of soil layers, $a_{r m s}$. This figure can be compared to the well-known findings of Idriss (1990), such as, plots peak ground acceleration (PHA) on rock versus PHA on soft soil (accounting for the fact that peak accelerations correlate well with rms accelerations, at least, in the case of the Chi-Chi earthquake). As a whole, the dependence shown in Fig. 4.2h agrees well with Idriss's data, but two points with increased $\left(\mathrm{a}_{\text {rms }}\right) \mathrm{S}$ values attract attention, which correspond to TCU065 and TCU072 sites, where subsurface soils possess strong hard-type nonlinear behavior. Our previous experience in studying soil behavior during strong earthquakes shows that we can almost always find areas in the closest vicinities of the fault plane, where soils possess such behavior.

Amplification of oscillations on the surface resulted from resonant phenomena in subsurface soils and hard-type soil nonlinearity are also observed at other near-fault sites, such as, CHY101 (Fa 1.5), CHY036 (Fa 2.4), TCU102 (Fa 1.4), CHY104 (Fa 2.2), TCU115 (Fa 1.4), CHY074 (Fa 1.6), CHY002 (Fa 1.9), etc.

"Hard" character of soil response nonlinearity virtually disappears at distances of more than $\sim 12-15 \mathrm{~km}$ from the fault plane (Pavlenko \& Wen, 2008), because of the decrease of "input" motion intensity. At rather large distances from the fault, amplification of seismic oscillations results from two described above linear mechanisms; whereas nonlinear effects decrease with distance and can not effectively deamplify seismic oscillations any more.

\subsection{Stresses and strains induced in soil layers in near-fault zones during the Chi-Chi earthquake}

Analyzing stresses and strains induced in soil layers by the Chi-Chi earthquake, it is also reasonable to distinguish sites with "softer" $\left(\mathrm{V}_{\mathrm{s}-30} \leq 300 \mathrm{~m} / \mathrm{s}\right)$ and "harder" $\left(\mathrm{V}_{\mathrm{s}-30} \geq 450\right.$ 
m/s) soils. Fig. 4.3 represents estimated average (upper rows) and maximum (lower rows) stresses and strains induced in soil layers at the studied sites during the Chi-Chi earthquake.

Names of sites possessing "harder" subsurface soils are underlined. We can see from the figures that at the closest to the fault plane sites (within $\sim 20 \mathrm{~km}$ from the fault), resonant phenomena are observed in the upper soft soil layers (down to $\sim 40-60 \mathrm{~m}$ ), i.e., trapping of seismic waves due to the impedance contrast between softer and neighboring denser layers. Stresses in soil layers increased with depth, whereas maximum strains usually occurred in the upper 15-40 m of soil (Fig. 4.3). At sites, where soft surface layers with Vs-30 $\leq 300 \mathrm{~m} / \mathrm{s}$ were underlayed by denser layers, and impedance contrast was higher, resonant phenomena were more pronounced. Maximum strains were achieved at the closest to the fault plane sites, such as, TCU065, TCU110, TCU115, CHY101 ( 0.6-0.8\%), CHY025, and CHY036 ( 0.4-0.6\%). At other sites maximum strains in soil layers did not exceed $\sim 0.1-0.4 \%$. In (Pavlenko \& Wen, 2008) it is concluded that liquefaction phenomena occurred at TCU065, TCU110, TCU115, CHY101, CHY036, and CHY039 sites.

The obtained estimates of average stresses and strains induced in the upper $30 \mathrm{~m}$ of soil during the strong motion, $\tau_{30}$ and $\gamma_{30}$, are given in Table 4.1, and the distributions of these parameters around the fault plane are shown in Fig. 4.4a, b. As seen from the figures, areas of softer subsurface soils with $\mathrm{V}_{\mathrm{s}-30} \leq 300 \mathrm{~m} / \mathrm{s}$ in bajada, to the west of the fault, correspond to zones of decreased stresses and increased strains. Average stresses and strains in the upper $30 \mathrm{~m}$ of soil, $\tau_{30}$ and $\gamma_{30}$, are shown as functions of the distance from the fault (Fig. 4.4d) and as functions of the level of "input" motion to soil layers, rms accelerations $\mathrm{a}_{\text {rms }}$ (Fig. 4.4f). At sites with "softer" subsurface soils (shown by points in the figures), average stresses and strains decrease with distance (in Fig. 4.4d, the corresponding approximations by functions $\sim \mathrm{r}^{-1}$ are shown), and they increase with the level of "input" motion, however scattering of estimates around approximating linear functions is rather large. At sites possessing "harder" subsurface soils, average stresses and strains (shown by circles) deviate from power functions and appreciably increase scattering. At these sites, average stresses are higher and average strains are lower than at sites with "softer" subsurface soils.

Average stresses and strains in the upper soil layers depend on the distance from the fault plane (the level "input" of motion), as well as on the mechanical parameters of a soil ( $\mathrm{V}_{\mathrm{S}}$ and densities). Stresses and strains naturally decrease with increasing distance from the fault, and, at the same time, stresses $\tau_{30}$ increase, and strains $\gamma_{30}$ decrease with increasing $\mathrm{V}_{\mathrm{s}-30}$. Decreased stress values at some sites in the vicinity of the fault (for example, at $\mathrm{CHY092}$ and CHY002) are obviously related to decreased $\mathrm{V}_{\mathrm{s}-30}$ values in the upper layers at these sites, whereas decreased strains values of at some other sites (for example, at TCU116, TUC138, TCU082, and TCU054) are due to relatively high $\mathrm{V}_{\mathrm{s}-30}$ in the upper soil layers at these sites.

Thus, according to the obtained estimates, at sites possessing "softer" soils, average strains decrease with distance from the fault more quickly than average stresses, probably because stresses in soil layers are defined to a larger extent by radiation from the earthquake source (level of "input" motion to soil layers) than by mechanical properties of soils, whereas strains more depend on soil properties, i.e., on resonant phenomena in upper soil layers. 


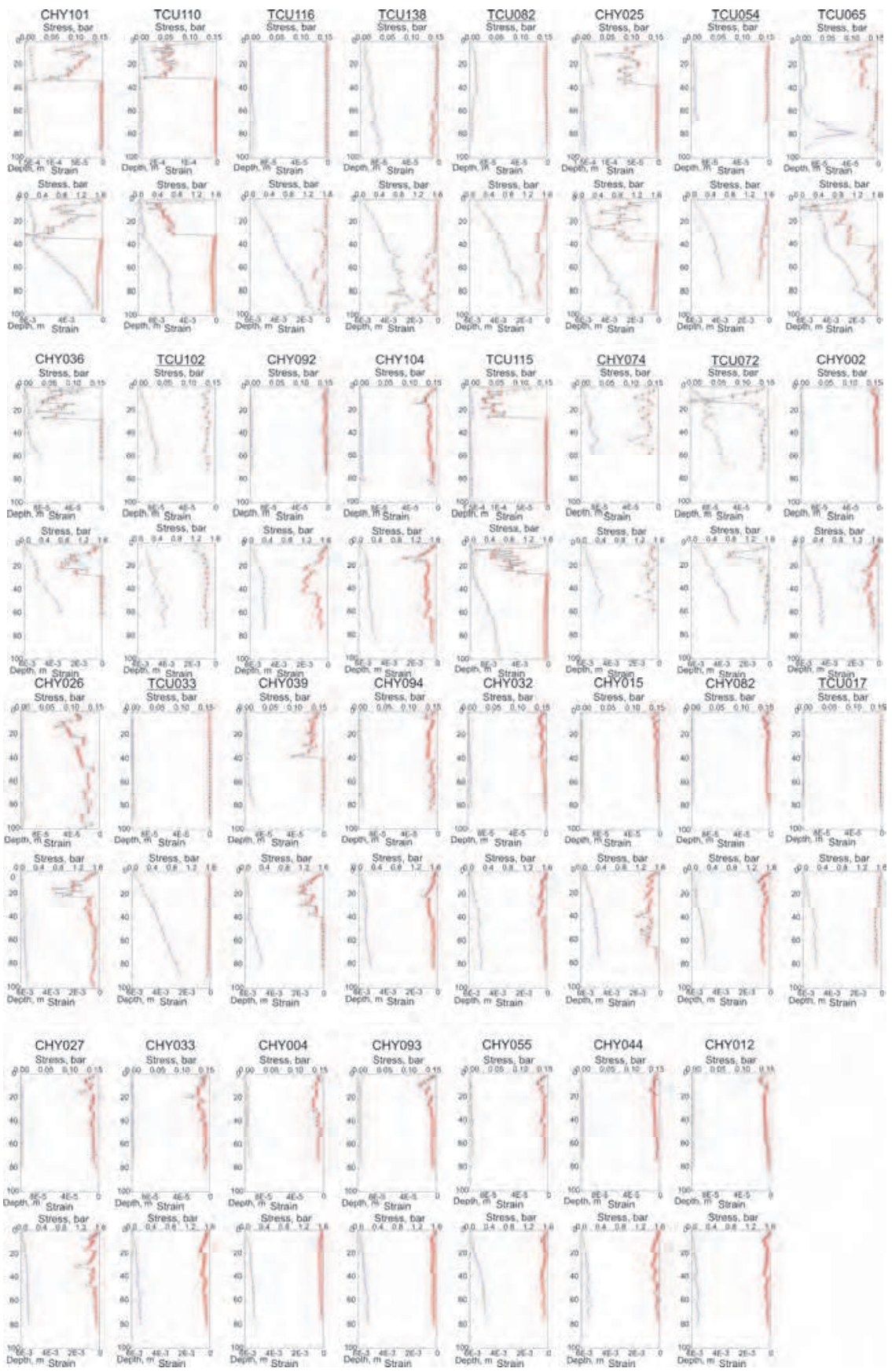

Fig. 4.3. Estimated average (upper rows) stresses (dash lines) and strains (solid lines), induced in soil layers during the Chi-Chi earthquake. 

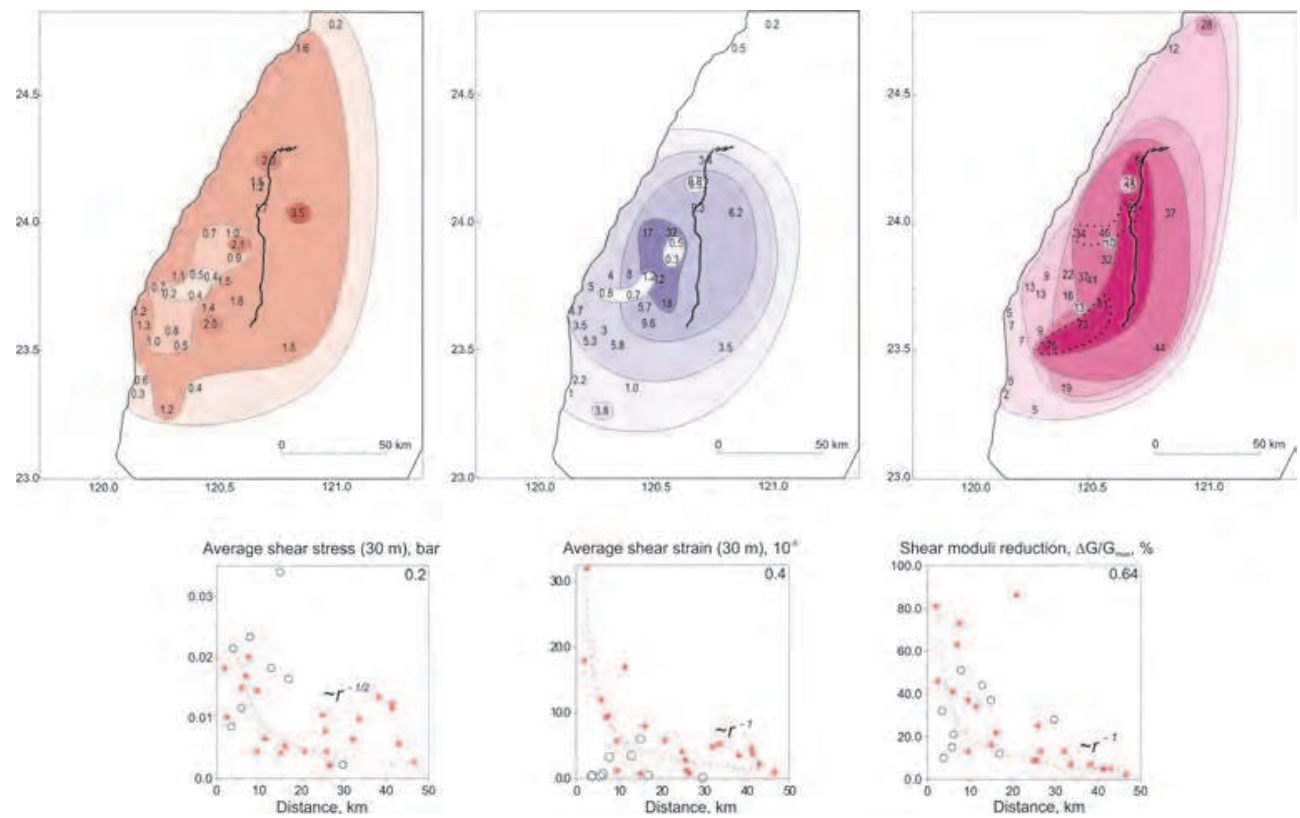

Fig. 4.4. Upper row: distribution around the fault plane of (a) - average stresses in the upper $30 \mathrm{~m}$ of soil $\tau_{30},(\mathrm{~b})$ - average strains in the upper $30 \mathrm{~m}$ of soil $\gamma_{30},(\mathrm{c})$ - estimates of shear moduli reduction in the upper $30 \mathrm{~m}$ of soil $\Delta G / G_{\max -30}$ (dotted lines indicate areas showing signs of soil liquefaction). Lower row: (d) - average stresses $\tau_{30},(\mathrm{e})$ - average strains $\gamma_{30}$, (f) - estimates of shear moduli reduction $\Delta G / G_{\max -30}$ as functions of the distance from the fault.

\subsection{Shear moduli reduction in soil layers in near-fault zones during the Chi-Chi earthquake}

As concluded in (Pavlenko \& Wen, 2008), at the closest to the fault plane sites soil behavior during the Chi-Chi earthquake was substantially nonlinear. Nonlinearity of soil response can be characterized by reduction of shear moduli in soil layers (Pavlenko \& Irikura, 2005). Thus, the constructed models of soil behavior were used for estimating shear moduli reduction in the upper $30 \mathrm{~m}$ of soil, $\Delta \mathrm{G} / \mathrm{G}_{\max -30}$. The obtained estimates are presented in Table 4.1; Fig. 4.4c, e, g show the distribution of $\Delta \mathrm{G} / \mathrm{G}_{\max -30}$ estimates around the fault plane, and the dependencies of the estimates on the distance from the fault and on the level of "input" motion to soil layers, respectively.

The evaluated values of $\Delta \mathrm{G} / \mathrm{G}_{\max -30}$ testify to high nonlinearity of soil response during the Chi-Chi earthquake: in the closest vicinity of the fault plane, at TCU110, CHY025, TCU065, TCU102, and CHY074 sites, shear moduli reduction in the upper $30 \mathrm{~m}$ achieved $\sim 40-50 \%$ (Fig. 4.4c, e; Table 4.1). The highest $\Delta \mathrm{G} / \mathrm{G}_{\max -30}$ values were obtained at CHY101, CHY036, and CHY039 sites, where the constructed models of soil behavior show substantial differences in the shapes of stress-strain curves at the beginning and at the end of the strong motion, indicating softening (probably, liquefaction) of surface layers. This area is marked by a dotted line in Figs 4.1 and 4.4 c. 
High values of shear moduli reduction $\Delta G / G_{\max -30} \sim 30-50 \%$ were obtained in the closest vicinity of the fault (within $\sim 25 \mathrm{~km}$ from the surface rupture) at "soft" soil sites: TCU102, TCU110, TCU115, TCU072, CHY074, TCU116, CHY025, and CHY092 (Fig. 4.4c). At sites TCU138, TCU082, TCU054, and TCU033, possessing "harder" subsurface soils $\left(\mathrm{V}_{\mathrm{s}-30} \sim 450\right.$ $605 \mathrm{~m} / \mathrm{s}$ ), lower values of shear moduli reduction were obtained: $\Delta \mathrm{G} / \mathrm{G}_{\max -30} \sim 10-20 \%$. At sites CHY104, CHY002, CHY026, CHY094, and CHY032, shear moduli reduction can be underestimated because of the presence of basin-induced surface waves in records (Fig. 4.1), which noticeably increase amplitudes of oscillations on the surface and can not be simulated in our one-dimensional problem (Pavlenko \& Wen, 2008).

With increasing distance from the fault, shear moduli reduction values decrease down to $\sim 10 \%$ at $35-50 \mathrm{~km}$ and to $\sim 5 \%$ at $50-70 \mathrm{~km}$ from the fault (Fig. $4.4 \mathrm{c}$, e), where soil response becomes virtually linear.

In Fig. 4.4e, g shear moduli reduction values for "softer" and "harder" sites are shown by points and by circles, respectively. It is seen from the plots that shear moduli reduction estimates at "softer" sites decrease with distance approximately as $\sim \mathrm{r}-1$ and they grow in proportion to the level of "input" motion to soil layers. Points, noticeably deviating from the approximating functions, correspond to $\mathrm{CHY039}$ and $\mathrm{CHY} 036$ sites with increased $\Delta \mathrm{G} / \mathrm{G}_{\text {max- }}$ 30, where the constructed models of soil behavior show liquefaction phenomena, and to

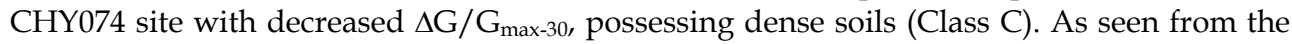
plots, $\Delta \mathrm{G} / \mathrm{G}_{\max -30}$ estimates at "harder" sites substantially increase scattering of points around the approximating relationships (Fig. 4.4e, g).

Thus, reduction of shear moduli in the upper $30 \mathrm{~m}$ of soil at "softer" sites can be rather accurately described as a function, inversely proportional to the distance from the fault, $\sim \mathrm{r}$ -1 and as a linear function of the level of "input" motion, $\mathrm{a}_{\mathrm{rms}}$. As mentioned above, strong ground motion during the Chi-Chi earthquake induced resonant amplification of seismic oscillations in the upper soft layers at many sites, and since soil conditions were similar at soil sites located mostly to the south and south-west of the fault (Fig. 4.1), average strains in the upper $30 \mathrm{~m}$ are proportional to the level of "input" motion to soil layers, and their decrease with distance from the fault can be approximately described as $\sim \mathrm{r}-1$. Accordingly, shear moduli reduction values depend on distance and on the level of "input" motion in the same manner.

At the same time, at sites with "harder" subsurface soils, resonant phenomena were not observed in the upper $30 \mathrm{~m}$ of soil (according to our estimates, maximum strains at these sites correspond to depths of $\sim 40 \mathrm{~m}$ and more (Fig. 4.3)), and estimates of shear moduli reduction depend not only on the distance from the fault (or on the level of "input" motion), but, to a greater extent than for "softer" soils, on the profiling data, which are very diverse at these sites, dispersed over a large area around the fault. Consequently, shear moduli reduction values can be quite different even at sites located at the same distances from the fault.

\subsection{Nonlinear components of soil response in near-fault zones during the Chi-Chi earthquake}

To estimate nonlinear components of soil response, models of soil behavior constructed in (Pavlenko \& Wen, 2008) were tested by the Gaussian white noise. Linear and nonlinear components of soil response were distinguished, and their intensities were estimated in percent of the whole intensity of the response. The obtained estimates are given in Table 4.1. 
Soft soils in the closest vicinity of the fault possess the highest nonlinearity of the response: according to our estimates, the whole nonlinear components of soil response achieve $\mathrm{Nl} \sim$ $60-80 \%$, and nonlinear quadratic and cubic components are up to $\sim 12-16 \%$ of the intensity of the response. At the same time, nonlinear residual components of soil response related to higher-order nonlinearities (the 4 th order and higher) are also high, up to $\sim 30-40 \%$ of the intensity of the response. Evidently, this indicates very high nonlinearity of soil response in near-fault zones during the Chi-Chi earthquake.

With increasing distance from the fault plane, nonlinear components of soil response decrease, and their dependence on distance can be described in the same manner as for other parameters, such as, approximately $\sim \mathrm{r}^{-1}$. Accounting for sites possessing "harder" subsurface soils substantially increases scattering of points around the approximating functions. For sites with "softer" subsurface soils, the dependencies of the obtained estimates of nonlinear components on the level of "input" motion can be approximately described by linear functions. This is in agreement with our representations of soil nonlinearity: at soft soils, manifestations of nonlinearity increase with the level of "input" motion, i.e., with approaching to the fault.

At two closest to the fault plane sites possessing "harder" subsurface soils, such as, TCU072 and TCU102, nonlinearity of soil response was also high, evidently because of expressed resonant phenomena in the upper soft soil layers. At TCU072 site, resonant amplification of seismic oscillations occurred in the upper $\sim 11 \mathrm{~m}$ of colluvium $\left(\mathrm{V}_{\mathrm{S}} \approx 250 \mathrm{~m} / \mathrm{s}\right.$ ), and at TCU102 site, resonant phenomena were related to the upper $\sim 4-6 \mathrm{~m}$ of soft silty soils, which were softened during the strong motion. The behavior of these upper soft layers was substantially nonlinear and described by very sloping stress-strain relations (Pavlenko \& Wen, 2008). Since surface soft layers were underlayed by hard breccia (at TCU072) and gravel (at TCU102), average S-wave velocities in the upper $30 \mathrm{~m}$ were higher than $\sim 300 \mathrm{~m} / \mathrm{s}$ at both sites, and the sites were assigned as possessing "harder" subsurface soils, however, nonlinear components at these sites satisfy regularities obtained for sites possessing "softer" subsurface soils. With increasing distance from the fault, nonlinearity of soil response decreases and at distances of $\sim 40-50 \mathrm{~km}(\sim 1 / 2$ of the length of the fault plane), nonlinear components in soil response do not exceed $10-15 \%$, according to our estimates.

\section{Conclusions}

Experimental data provided by recent large earthquakes, such as, the 1994 Northridge earthquake $\left(\mathrm{M}_{\mathrm{W}} \sim 6.7\right)$, the 1995 Kobe $\left(\mathrm{M}_{\mathrm{W}} \sim 6.8\right)$ and 2000 Tottori $\left(\mathrm{M}_{\mathrm{W}} \sim 6.7\right)$ Japanese earthquakes, the 1999 Chi-Chi $\left(\mathrm{M}_{\mathrm{W}} \sim 7.7\right)$ Taiwanese earthquake and others, have shown a clear evidence of the nonlinear behavior of subsurface soils in near-fault zones.

Acceleration records of the Kobe earthquake gave a bright illustration of the fact that in strong ground motion, maxima of energy of oscillations at soil sites shift to the lowerfrequency domain. The fact was explained by the nonlinearity of the soil response: mutual interactions of spectral components of seismic waves propagating in soil layers lead to redistribution of energy of oscillations over the spectral band, and spectra of signals on the surface tend to take the form $E(f) \sim f^{-k}$.

Numerous surface records obtained during the 1999 Chi-Chi (Taiwan) earthquake possess similar features, indicating nonlinearity of the soil response in many places near the fault plane. Although these records can not be analyzed in the same manner as records of the Kobe earthquake because of the absence of borehole data, we can suppose that certain typical nonlinear distortions occur in seismic waves of similar intensities in subsurface soils. 
Records of recent strong earthquakes, such as, the 1995 Kobe earthquake, the 2000 Tottori (Japan) earthquake, and the 1999 Chi-Chi (Taiwan) earthquake, were used to study the influence of nonlinearity of soil response on characteristics of ground motion.

In weak motion soil response can be considered as linear, whereas in strong motion it is nonlinear, and the degree of its nonlinearity depends on the intensity of oscillations. Nonlinearity of soil response leads to changes in spectra (which can be essential) and amplification of ground motion, as shown in the diagram:

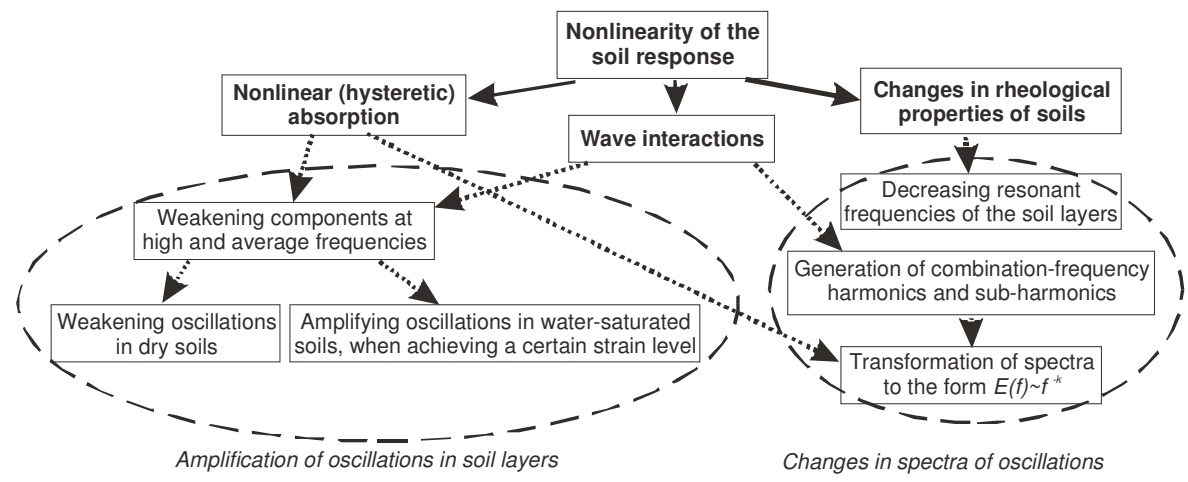

Fig. 5.1. Influence of nonlinearity of soil response on amplification and spectra of seismic waves propagating in soil layers.

In strong motion, nonlinear damping mechanisms are turning on, which lead to weakening of high- and average-frequency components. Low-frequency components are not weakened; they can be even amplified, because in cases when they were absent in input to soil layers they appear in the output, i.e., on the surface.

Changes in spectra of ground motion related to nonlinearity of soil response appear in shifting of resonant frequencies of soil layers to the low-frequency domain and in transformations of spectra of ground motion to the form $E(f) \sim f^{-k}$.

Amplification of seismic waves is decreased due to the nonlinearity of soil response (if compared with "linear" case) in dry soils (where the level of the underground water is lower than $\sim 10 \mathrm{~m}$ ) and, in lesser extent, in wet soils (where the level of the underground water is above $\sim 10 \mathrm{~m}$ ). In wet soils, nonlinear damping sometimes cannot compensate amplification of seismic waves resulting from (1) the transition of seismic waves to upper layers with smaller impedance values, and (2) resonant phenomena in the upper softer layers. As a whole, amplification can occur even in cases of high nonlinearity.

Thus, the degree of the nonlinearity of soil response depends on the composition of soil layers and on their saturation with water, as well as on the intensity and spectral composition of seismic waves, incident to soil layers. Since the composition and mechanical parameters of soils vary from place to place, any generalized dependencies of PGA (or oscillation intensity) on soils on magnitude-distance will surely possess large scatterings, which was noticed by many authors.

Therefore, the correct approach in seismic microzonation is calculation of space-dependent acceleration time histories of possible future strong earthquakes accounting for soil nonlinearity. The limitations of conventional programs for estimation of soil response are: underestimation of the degree of soil-response nonlinearity in near-fault zones, disregard of 
the differences in nonlinear behavior of cohesive and non-cohesive soils (soft-type, hardtype, liquefaction), and disregard of changes in rheological properties of the upper soft layers in strong ground motion. Soil response should be estimated by methods of nonlinear analysis accounting for all points mentioned above.

According to the obtained estimates, based on records of the Kobe (1995), Tottori (2000), and Chi-Chi (1999) earthquakes, during crustal earthquakes with magnitudes $\mathrm{M}_{\mathrm{w}} \sim 6.7-7.3$, strong nonlinearity of the soil response (changes in rheological properties of the upper soil layers and shear modulus reduction of $\sim 50-60 \%$ and more) are observed within an area up to $\sim 1 / 4$ of the length of the fault plane. Within this area, noticeable manifestations of soil nonlinearity are observed in the upper 15-25-60 m of the soil profiles. At distances of $\sim 1 / 2$ of the length of the fault, nonlinearity is much weaker, even in soft subsurface soils. Stressstrain relations, suggested by Hardin \& Drnevich (1972), adequately describe the behavior of soils at all depths in conditions of moderate dynamic loadings. In conditions of large loadings, in cases of strong nonlinearity, these stress-strain relations can be used to describe the behavior of dense soils at depths below some level, depending on the composition of the soil layers and their saturation with water, as well as on the magnitude and location of the earthquake; whereas the behavior of soft subsurface soils should be described by other, more "nonlinear" stress-strain relations. Such relations are found in this work.

Ignoring the features of soil behavior in strong ground motion leads to underestimation of maximum acceleration in near-fault zones, and mistaken estimates of spectra of oscillations on the surface at soil sites.

\section{Acknowledgments}

I thank Kansai Electric Power Company and Kobe City for acceleration records of the vertical arrays at SGK, TKS, and PI recording sites and I thank the website of the Kik-Net Digital Strong-Motion Seismograph Network for records of the 2000 Tottori earthquake and the profiling data. The profiling data at soil stations in Taiwan provided by NCREE are greatly appreciated. This study was partially supported by Grant-in-Aid for Scientific Research, No.11792026 and No.00099 (JSPS), from the Ministry of Education, Science, Sports, and Culture, Japan and by the National Science Council (Taiwan) under Grant No. NSC 952811-M-492-001.

\section{References}

Hardin, B. O. \& Drnevich, V. P. (1972), Shear modulus and damping in soils: Design equations and curves, Proc. Am. Soc. Civil Eng., J. Soil Mech. Found. Div., 98, 667-692.

Joyner, W. B. \& Chen, T. F. (1975), Calculation of nonlinear ground response in earthquakes, Bull. Seism. Soc. Am., 65, 1315-1336.

Marmarelis, P. Z. \& Marmarelis, V. Z. (1978), Analysis of Physiological Systems, The WhiteNoise Approach, Plenum Press, New York and London.

Pavlenko, O. V. \& Irikura, K. (2003), Estimation of nonlinear time-dependent soil behavior in strong ground motion based on vertical array data, Pure Appl. Geophys, 160, 23652379.

Pavlenko, O. V. \& Wen, K.-L. (2008), Estimation of Nonlinear Soil Behavior during the 1999 Chi-Chi, Taiwan, Earthquake, Pure Appl. Geophys., 165, 373-407. 


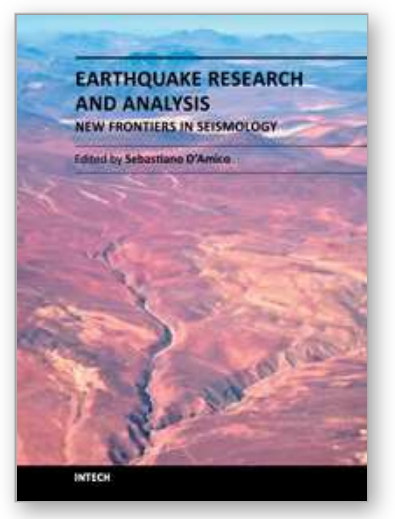

\author{
Earthquake Research and Analysis - New Frontiers in Seismology \\ Edited by Dr Sebastiano D'Amico
}

ISBN 978-953-307-840-3

Hard cover, 380 pages

Publisher InTech

Published online 27, January, 2012

Published in print edition January, 2012

The study of earthquakes combines science, technology and expertise in infrastructure and engineering in an effort to minimize human and material losses when their occurrence is inevitable. This book is devoted to various aspects of earthquake research and analysis, from theoretical advances to practical applications. Different sections are dedicated to ground motion studies and seismic site characterization, with regard to mitigation of the risk from earthquake and ensuring the safety of the buildings under earthquake loading. The ultimate goal of the book is to encourage discussions and future research to improve hazard assessments, dissemination of earthquake engineering data and, ultimately, the seismic provisions of building codes.

\title{
How to reference
}

In order to correctly reference this scholarly work, feel free to copy and paste the following:

Olga Pavlenko (2012). Influence of Nonlinearity of Soil Response on Characteristics of Ground Motion, Earthquake Research and Analysis - New Frontiers in Seismology, Dr Sebastiano D'Amico (Ed.), ISBN: 978953-307-840-3, InTech, Available from: http://www.intechopen.com/books/earthquake-research-and-analysisnew-frontiers-in-seismology/influence-of-nonlinearity-of-soil-response-on-characteristics-of-ground-motion

\section{INTECH}

open science | open minds

\section{InTech Europe}

University Campus STeP Ri Slavka Krautzeka 83/A 51000 Rijeka, Croatia Phone: +385 (51) 770447

Fax: +385 (51) 686166 www.intechopen.com

\section{InTech China}

Unit 405, Office Block, Hotel Equatorial Shanghai No.65, Yan An Road (West), Shanghai, 200040, China 中国上海市延安西路65号上海国际贵都大饭店办公楼 405 单元 Phone: +86-21-62489820

Fax: $+86-21-62489821$ 
(C) 2012 The Author(s). Licensee IntechOpen. This is an open access article distributed under the terms of the Creative Commons Attribution 3.0 License, which permits unrestricted use, distribution, and reproduction in any medium, provided the original work is properly cited. 